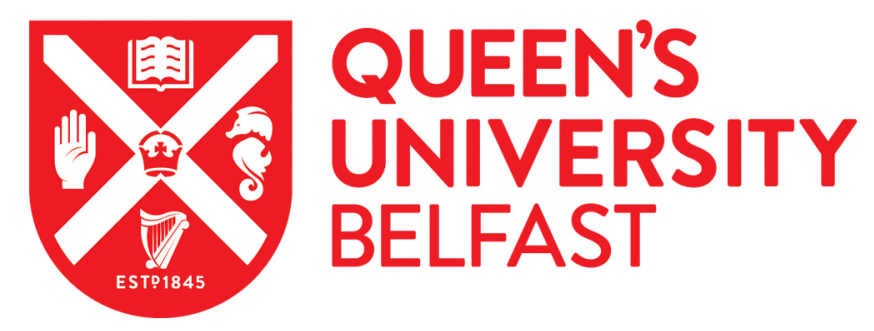

\title{
Comparison of optimal designs of steel portal frames including topological asymmetry considering rolled, fabricated and tapered sections
}

McKinstray, R., Lim, J. B. P., Tanyimboh, T. T., Phan, D. T., \& Sha, W. (2016). Comparison of optimal designs of steel portal frames including topological asymmetry considering rolled, fabricated and tapered sections. Engineering Structures, 111, 505-524. https://doi.org/10.1016/j.engstruct.2015.12.028

\section{Published in:}

Engineering Structures

\section{Document Version:}

Peer reviewed version

Queen's University Belfast - Research Portal:

Link to publication record in Queen's University Belfast Research Portal

\author{
Publisher rights \\ (c) 2016 Elsevier Ltd. This manuscript version is made available under the CC-BY-NC-ND 4.0 license http://creativecommons.org/licenses/by- \\ nc-nd/4.0/which \\ permits distribution and reproduction for non-commercial purposes, provided the author and source \\ are cited.
}

\section{General rights}

Copyright for the publications made accessible via the Queen's University Belfast Research Portal is retained by the author(s) and / or other copyright owners and it is a condition of accessing these publications that users recognise and abide by the legal requirements associated with these rights.

Take down policy

The Research Portal is Queen's institutional repository that provides access to Queen's research output. Every effort has been made to ensure that content in the Research Portal does not infringe any person's rights, or applicable UK laws. If you discover content in the Research Portal that you believe breaches copyright or violates any law, please contact openaccess@qub.ac.uk. 
Comparison of Optimal Designs of Steel Portal Frames Including Topological Asymmetry Considering Rolled, Fabricated and Tapered Sections

Ross McKinstray, James B.P. Lim, Tiku T. Tanyimboh, Duoc T. Phan, Wei Sha*

${ }^{*}$ Corresponding author

Ross McKinstray: SPACE, David Keir Building, Queen's University, Belfast, BT9 5AG, UK. James B.P. Lim: SPACE, David Keir Building, Queen's University, Belfast, BT9 5AG, UK. Tiku T. Tanyimboh: Department of Civil and Environmental Engineering, University of Strathclyde, James Weir Building, 75 Montrose Street, Glasgow, G1 1XJ, UK.

Duoc T. Phan: Department of Civil and Construction Engineering, Faculty of Engineering and Science, The Curtin University Sarawak, Miri 98009, Malaysia.

Wei Sha: SPACE, David Keir Building, Queen's University, Belfast, BT9 5AG, UK. Email: w.sha@qub.ac.uk 


\title{
Comparison of Optimal Designs of Steel Portal Frames Including Topological Asymmetry Considering Rolled, Fabricated and Tapered Sections
}

\begin{abstract}
A structural design optimisation has been carried out to allow for asymmetry and fully tapered portal frames. The additional weight of an asymmetric structural shape was found to be on average 5 to $13 \%$ with additional photovoltaic (PV) loading having a negligible effect on the optimum design. It was also shown that fabricated and tapered frames achieved an average percentage weight reduction of $9 \%$ and $11 \%$, respectively, as compared to comparable hot-rolled steel frames. When the deflection limits recommended by the Steel Construction Institute were used, frames were shown to be deflection controlled with industrial limits yielding up to $40 \%$ saving.
\end{abstract}

Keywords: Hot-rolled steel; Fabricated beams; Portal frames; Genetic algorithms; Serviceability limits; Buckling limits

\section{Introduction}

For steel portal frames, a recent paper [1] has shown that asymmetric shapes with photovoltaic (PV) panels on the southward side were advantageous for a low energy driven design. Asymmetry and PV panels allowed for reduced embodied energy solutions (less insulation) to achieve zero carbon standing by increased PV renewable space. The increased degree of asymmetry was shown to be very useful for zero carbon building code compliance where a calculated degree of asymmetry (from an energy simulation optimisation) could be used to meet zero carbon requirements.

In another recent paper [2], a framework for a structural design optimisation for symmetrical portal frames that used S275 steel was presented that considered frames from rolled sections and frames from fabricated sections. This present paper now investigates the effect 
of asymmetry [1] on the structural design optimisation with photovoltaic panels on the southward side of weight $0.4 \mathrm{kN} / \mathrm{m}^{2}$. Two frame configurations are considered; symmetric frames and asymmetric frames with an apex ratio of 0.8 . Within the design optimisation, a decoupled approach from the energy optimisation is taken with the main goal to establish the effect of asymmetry on the optimisation. No attempt is made to link the structural design optimisation to energy optimisation as it was shown that the steel weight would have an insignificant effect on the energy design.

The frame constructions in this paper differ from those by McKinstray et al. [2] due to the asymmetry and the additional tapered frame GA configurations case. Tapered frames [3], [4] are the more efficient type of portal frame as these allow the cross-section to vary as required [5] rather than being limited to a single critical ultimate limit state (ULS) load position that would control a frame made from rolled or fabricated I sections. This present paper investigates the structural effect of this asymmetry on the structural members. An optimisation framework is described to design portal frames for minimum primary member weights in accordance with the Eurocodes. Unlike [2], S355 steel is used as it has become common practice to use this grade in portal frames due to its availability and similar price to S275. Although it does not provide any benefits in terms of reducing deflections, the additional yield strength can be useful in reducing buckling. For each of the construction methods, a single optimisation configuration case is used (see Figure 1 and below);

C1 - Rolled I beam sections (selected from the Tata Steel bluebook [6]). This configuration has 6 decision variables

C2 - Fabricated I sections (I beams fabricated from 3 plates). This configuration has 12 decision variables

C3 - Fully fabricated tapered frames (I beams fabricated from 3 plates but with varying section depth). This configuration has 15 decision variables 
As mentioned earlier, the addition of PV is accounted for through increased permanent loading on the southward side, represented by an additional $0.4 \mathrm{kN} / \mathrm{m}^{2}$. In addition, the effects of wind loading are added to the list of considered load combinations. Asymmetry also increases the severity of a load occurring only on one side of the frame. To address this, load combinations are considered with loads present on one side as well as both sides of the roof. These result in 120 load combinations, including 28 serviceability limit state (SLS) combinations (14 load combinations for differential deflection limit, 14 for absolute deflection limit) and 92 ULS combinations. The deflection limits recommended by the Steel Construction Institute (SCl) [7] are adopted; a comparison is also made to the less conservative limits from the industry [8] in Section 2. The effects of the additional wind load combinations beyond the gravity load combination used by McKinstray et al. [2] are investigated in Section 2 also, for frame moments.

A wide range of topologies as well as different ranges of variable and permanent actions are considered. The controlling load combinations were identified at positions through the frame as well as the increase in moment at the column tops. It was found that wind loading can increase maximum design moments in the column tops by a factor from 1 to 3 , depending on the span and column height.

A reference frame configuration is optimised, with a span of $35 \mathrm{~m}$ and column heights of 6 and $12 \mathrm{~m}$ (see Section 4). It is optimised for symmetric and asymmetric configurations with apex ratios of 0.5 and 0.8 respectively [1]). The influence of the combination of wind loading, PV loading and asymmetry on the primary steel mass for the reference frame is established. It is shown that the $\mathrm{SCl}$ serviceability limits greatly control the design and that with deflection limits the additional PV loading has a negligible effect on the optimum primary member weight.

A topographical parametric study is then described (Section 5) covering different spans (14.5 to $50 \mathrm{~m}$ ) and column heights (4 to $11.4 \mathrm{~m}$ ) for different site locations (wind speeds) and 
displacement limits ( $\mathrm{SCl}$ and Industrial limits). Here, the effects of wind loading, asymmetry and deflection limits are investigated. It was found that wind load has a significant effect on the optimisation compared to just the gravity load combination. Tapered sections were found to allow for additional weight savings ( $2-10 \%$ extra) compared to fabricated sections. The effect of asymmetry is shown to be small with average weight increase of $4-13 \%$, with the smallest increase found in tapered frames followed by rolled sections and then fabricated sections.

\section{Limits state design}

Modern practice has shown that plastic design produces the most efficient designs in the majority of cases [9], [10]. Elastic design is still used, particularly when serviceability limit state deflections will control frame design [8], [11], [12]. Phan et al. [8] and McKinstray et al. [2] both demonstrated that if the deflection limits recommended by the $\mathrm{SCl}$ are adopted, serviceability limit states control design. In addition, deep fabricated sections tend to be incapable of fully utilising the material in the cross-section beyond the elastic modulus. Additionally tapered sections are also generally not considered suitable for plastic design. Therefore, elastic design is used here. A frame analysis program, written by the authors in MATLAB, was used for the purpose of the elastic frame analysis. The internal forces, namely, axial forces, shear forces, and bending moments can be calculated at any point within the frame. The MATLAB program was capable of capturing the behaviour of tapered members.

\subsection{Frame loading types}

A number of load combinations [13] must be verified in the design of steel portal frames. This is obtained through the rules for actions found in BS EN 1991 [14] and the rules for combinations of actions in BS EN 1990 [15]. The combination of actions is the combination of permanent, variable snow and wind actions on the structure multiplied by load factors determined from the design code. 
Permanent actions are the self-weight of the structure including primary steelwork, purlins and secondary steel $\left(0.1 \mathrm{kN} / \mathrm{m}^{2}\right)$, cladding materials $\left(0.2 \mathrm{kN} / \mathrm{m}^{2}\right)$, building services $(0.25$ $\left.\mathrm{kN} / \mathrm{m}^{2}\right)$ and photovoltaic panels and services $\left(0.4 \mathrm{kN} / \mathrm{m}^{2}\right)$. Permanent loads are determined from the manufacturer's specification and are identical to [2], apart from the additional PV loading that is included on a single roof side. In addition, variable actions including access, wind and snow are considered. Snow loading is calculated based on BS EN 1991-1-3 [16] and its National Annex [17], assuming that a non-accidental case (drift) of $0.4 \mathrm{kN} / \mathrm{m}^{2}$ is typical. Loads on roofs that are not accessible, except for normal maintenance and repair, are classed under category $\mathrm{H}$ in BS EN 1991-1-1 [14]. For that category of roof, the UK National Annex to BS EN 1991-1-1 [18] gives a variable loading of $0.6 \mathrm{kN} / \mathrm{m}^{2}$ for slopes under $30^{\circ}$.

Wind actions are calculated according to BS EN 1991-1-4 general actions wind actions [19]. Four wind cases are considered based on 360 degree wind calculation method and an additional 2 cases with wind direction reversed to account for the asymmetric shape. For simplicity, no account is taken for the effect of asymmetry on the calculation of the wind pressures on the frame. In asymmetric frames the loading calculated for an equivalent symmetric frame is used. Additionally, the largest zone values are used instead of the higher localised values. Table 1 outlines the assumptions used in the calculation of wind forces on the building located in Belfast using the largest wind zones. Calculations are also made for Liverpool and Birmingham, which are used later in Section 5.4. The peak velocity pressure is dependent on the topography (span \& column height). Due to the nature of the code, Liverpool and Birmingham peak velocity pressures are scalable. For example if Belfast had a dynamic wind pressure of $1.3 \mathrm{kN} / \mathrm{m}^{2}$, Liverpool and Birmingham would be 1.0 $\mathrm{kN} / \mathrm{m}^{2}$ and $0.8 \mathrm{kN} / \mathrm{m}^{2}$, respectively.

\subsection{Frame load combinations}

Loads are factored together in accordance with EN1990 for ULS (Table 2). Equation 6.10 may be used solely as it is the most conservative of the three. For portal frames the benefits 
of the more economical Equations $6.10 \mathrm{a}$ and $6.10 \mathrm{~b}$ are generally not significant [12]. A number of standard ULS combinations exist (Table 3) for the design of symmetric portal frames [12] generated from Equation 6.10. When asymmetric frames are considered, additional loading conditions need to be considered. For symmetric frames it is reasonable to assume that the symmetric loading will produce the most onerous ULS combinations. However, for asymmetric frames with significant degrees of asymmetry this is less likely, making localised loading more significant. Examples include snow or access loading on a single side of the frame. As will be shown later in the paper, no snow loading is not considered as a dominate load case. Drive snow could be a topic of future research, but it would need to exceed the imposed loading for it to be dominant. It is normal practice to assume that there will be no imposed loading during storms or in snow conditions.

The addition of the photovoltaic panels adds loading to one side of the frame and so needs to be considered in conjunction with the other load combinations, as well as the possibility of the photovoltaic panels being removed. To account for the identified loading conditions the standard ULS load combinations in Table 3 are expanded to include the asymmetric conditions (Table 4). Combinations 1 and 2 in Table 3 are reduced to just combination 1 as access load is the dominant of the two.

\subsection{Importance of additional wind load combinations}

The additional load combinations (generated from the wind) can be visualised in an exemplar $35 \mathrm{~m}$ span frame with $6 \mathrm{~m}$ column height and apex ratio of 0.7 . Loading is calculated as outlined in Section 2.1, with wind loading calculated for Belfast. Figure 2a shows the bending moments for the analysis. Each green line indicates an individual load combination (LC) bending moment diagram. The thick outer line shows the ULS condition for all the combinations combined (bending moment envelope). The thicker blue line is load combination LC1 (gravity load combination) for comparison. For this frame configuration there are minor differences between the gravity load combination (LC1) and the additional load combinations in terms of maximum moments or general moment shape. 
When optimising tapered frames the point of contraflexure is important, as under a single load combination this point will have zero bending moment. However, it was found from Figure $2 a$ that this effect of the point of contraflexure is not valid for design practice, since significant bending moments are obtained from the other load combinations. If a small number or the single gravity load combination was used in an optimisation, dangerously small moments would be used in the verification of bending and buckling in the segment surrounding the point of contraflexure.

Frames using rolled or fabricated I sections are not affected by the point of contraflexure moving as the cross-section is constant across the frame, and is capable of carrying the larger bending moment elsewhere successfully. This can make the additional load combinations critical in controlling the minimum section size within the rafter for tapered frames. Conservatively it is possible to base the design on the moment envelope (thick black outer line) and not on a single load combination.

\subsection{Serviceability and ultimate limit state design requirements}

Serviceability deflection limits were calculated based on 14 differential and 14 absolute load combinations, as seen in Table 5. Based on these load combinations, deflection limits recommended by the SCI [7] or from industry [8] were adopted where stated (see Table 6). Secondly, considering ultimate limit state design, structural members are designed to satisfy the requirements for local capacity in accordance with Eurocode 3 [20]. Specifically, members are verified for capacity under shear, axial, moment, and combined moment and axial force. For fabricated and tapered beams, the buckling curves used are taken in accordance with the UK National Annex [21]. The frame is split into a number of segments (each with 5 nodes) between restraint positions. Each segment is then checked at each node position for the maximum and minimum (reversed moment) ULS load combination (for local capacity and buckling across the whole segment). This differs from [2] where buckling was only evaluated at specified positions. Here, it is checked in every segment. 


\subsubsection{Shear capacity}

The shear force, $V_{E d}$, should not be greater than the shear capacity, $V_{p l, R d}$;

$$
V_{E d} \leq V_{p l, R d}
$$

The shear capacity is given by:

$$
V_{p l, R d}=\frac{A_{v}\left(\frac{f_{y}}{\sqrt{3}}\right)}{\gamma_{M_{0}}}
$$

where

$$
\begin{aligned}
& f_{y} \quad \text { is the yield stress of steel } \\
& A_{v} \quad \text { is the shear area } \\
& \gamma_{M_{0}} \quad \text { is partial factor for resistance }
\end{aligned}
$$

\subsubsection{Axial capacity}

The axial capacity should be verified to ensure that the axial force $N_{E d}$ does not exceed the axial capacity $\left(N_{R d}\right)$ of the member.

$$
N_{E d} \leq N_{R d}
$$

\subsubsection{Moment capacity}

The bending moment should not be larger than the moment capacity of the cross section, $M_{p l, R d .}$

$$
M_{E d} \leq M_{p l, R d}
$$

where

$M_{E d} \quad$ is the moment applied to the critical section 


$$
M_{p l, R d} \text { is the moment capacity of the section. }
$$

Where members are subject to both compression and bending, the moment capacity $M_{p l, R d}$ is reduced if the axial force is significant in accordance with clause 6.2 .9 of Eurocode 3 Part $1-1[20]$

\subsubsection{Buckling}

The frame is split up into a series of segments between full restraints. Full restraints are provided by ties joining the compression flange to secondary steelwork (purlins). Irrespective of whether the frame is rolled, fabricated or tapered the segments are made based on a $0.75 \mathrm{~m}$ and $1 \mathrm{~m}$ fixed spacing at the column tops, $3 @ 1.5 \mathrm{~m}$ spacing at the eave, and $1 @ 1.5 \mathrm{~m}$ spacing at the apex (see Figure 3). Additionally a full restraint is provided at any point where the tapered gradient changes (end of haunches). Outside of these fixed spacing locations, full restraints are provided, with a maximum of $3 \mathrm{~m}$ in the columns and 4 $m$ in the rafters.

Each segment is then verified based on the cross-sectional properties and individual restraint spacing (at both ends of the segment). For segments where the cross-sectional depth variation is less than $3 \%$, buckling is verified using equations 6.61 and 6.62 of Eurocode 3 [20]. Manufacturing tolerances of rolled beams is approximately $1 \%$ of the height [22]. Over a segment length, height variations under $3 \%$ have more in common with uniform beams rather than tapered sections. As the frame is under single axis bending the additional second axis bending terms can be removed resulting in Equations 5 and 6 below [12].

$$
\begin{aligned}
& \frac{N_{E d}}{N_{b, z, R d}}+k_{z y} \frac{M_{y, E d}}{M_{b, R d}}-1 \leq 0 \\
& \frac{N_{E d}}{N_{b, y, R d}}+k_{y y} \frac{M_{y, E d}}{M_{b, R d}}-1 \leq 0
\end{aligned}
$$


The equivalent uniform moment factors $k_{z y}$ and $k_{y y}$ (interaction factors) are calculated based on the Annex B method of Eurocode 3 [20]. The maximum and minimum (reversed) bending moments are both verified independently. The restraint spacing $\left(L_{c r}\right)$ used in the calculation of stability based unity factors is based on the bending moment. Where the bending moment is positive with the bottom/internal flange in compression the segment length is used. This is the distance between full restraints. When the moment is reversed and the bottom/internal flange is in tension, the smaller of the maximum purlin spacing $(1.5 \mathrm{~m})$ or segment length is used. No attempt is made to take advantage of any beneficial effect of restraints on the tension flange. In-plane stability is verified using a buckling length of half the span, irrespective of asymmetry within the frame.

For segments where the cross-sectional depth variation is more than $4 \%$ the segment is verified using Equation 7 from NZS 3404:Part1:1997 Steel Structures Standard [23]. Design element lengths are calculated in the same manner for uniform sections. The NZS 3404 method has been shown to be conservative for tapered sections [24] but does not need a complex buckling analysis which would be infeasible for optimisation purposes. Other possible methods for addressing stability, although not implemented here, include [25]-[27].

$$
M_{b x}=\alpha_{m} \alpha_{s} M_{s x} \leq M_{s x}
$$

where

$$
\begin{aligned}
& \alpha_{m} \quad \text { is moment modification factor } \\
& \alpha_{s} \quad \text { is slenderness reduction factor } \\
& M_{s x} \quad \text { is normal sectional moment capacity } \\
& M_{b x} \quad \text { is design sectional moment capacity. }
\end{aligned}
$$




\subsection{Identification of critical ULS load combinations}

A study was conducted investigating 25600 frame configurations, based on the parameters shown in Table 7, for each of the 92 ULS load combinations (Table 4). In each frame configuration the critical or influential load combinations were recorded based on the bending moment (at the level of the individual node). For the range of loading and building shapes the maximum and minimum bending moments were recorded at each of the nodes with the corresponding load LC value. Cross-section dimensions were based on optimum design of symmetric portal frames using rolled sections [2]. Asymmetric frames were assumed to have the same sections as the symmetric counterparts.

The frame was split into 4 quadrants: the 2 columns and the left and right rafters. Within each quadrant, for both the maximum and minimum (reversed) bending moments the LC identifier was recorded at each node. The number of occurrences that each load combination controlled a node (in terms of $\%$ influence of all nodes in that quadrant) was then reported (Table 8). A total of 33 unique ULS load combination cases were found to be influential out of the possible $92(\approx 36 \%)$. If only symmetric frames are considered the number of influential load combinations drops to 30 . The frame asymmetry shape caused additional influencing combinations for the frame geometry. The majority of influential load combinations occur in the left hand side of the frame where the maximum bending moment and the minimum (reversed) bending moment occurred. The remainder of the quadrants were influenced by under 5 load combinations.

A key observation in the study was the large variations in the distances between the more traditional ULS gravity load combination LC1 and in some cases with wind included. In the previous example (seen in Figure 2a), the variation between the envelope and the ULS gravity combination LC1 (blue line) is small but this is not always the case (see Figure 2b). The wind forces are large in comparison to the other actions, in frames with relatively high column heights to span ratio. Here, the wind forces are larger and have more influence, leading to much larger moments as compared to the gravity load combination. 
The influence of the wind on the ULS moments compared to the gravity load combination was calculated for the range of building configurations by comparing the maximum moment at the column top between the wind load combinations (LC9-92) and the gravity load combination (LC1). The ratios are reported in Figure 4 for symmetric frames. It can be seen that for frames with long span and short columns, higher wind has very little influence on the ULS design of the frame. However, there is an exponential increase in the influence of the wind for short frames with high column heights.

This increase in moment can be very significant conceivably requiring considerably larger sections to carry the increased moments. This would call into question the validity of gravity load combination based optimisation as any result could be misleading requiring larger sections than would be expected. Particularly, most frames are deflection controlled which allows for some additional moment carrying capacity. However, the wind load combinations will also increase the deflections resulting in inevitable larger sections as there will be no additional deflection capacity in optimum designs.

\section{GA optimisation}

\subsection{Optimisation model}

The objective of the overall design optimisation is to determine the steel frame with the minimum primary member steel material weight, whilst satisfying the design requirements.

Previous optimisation research has been carried out for steel frames and truss structures [28]-[32] but not on portal frames with asymmetry and tapering. The weight of the frame depends on the cross-section sizes of members. The objective function is expressed in terms of the weight of the primary members per square metre of the floor area. The weight was based on the summation of the volume of steel material throughout the frame.

The unity factors and geometric limits for design constraints are as follows. 
(1) For each segment:

$$
\begin{aligned}
& g_{1}=\frac{V_{E d}}{V_{p l, R d}} \leq 1 \\
& g_{2}=\frac{V_{E d}}{V_{p l, R d}} \leq 1 \\
& g_{3}=\frac{N_{E d}}{N_{R d}} \leq 1 \\
& g_{4}=\frac{M_{E d}}{M_{p l, R d}} \leq 1
\end{aligned}
$$

(2) For segments with uniform section profile:

$$
\begin{aligned}
& g_{5}=\frac{N_{E d}}{N_{b, z, R d}}+k_{z y} \frac{M_{y, E d}}{M_{b, R d}} \leq 1 \\
& g_{6}=\frac{N_{E d}}{N_{b, y, R d}}+k_{y y} \frac{M_{y, E d}}{M_{b, R d}} \leq 1
\end{aligned}
$$

(3) For segments with tapered section profile:

$$
g_{5}=g_{6}=\frac{M_{E d}}{M_{b x}} \leq 1
$$

(4) Whole frame displacements:

$$
\begin{gathered}
g_{7}=\frac{\delta_{e}}{\delta_{e}^{u}} \leq 1 \\
g_{8}=\frac{\delta_{a}}{\delta_{a}^{u}} \leq 1
\end{gathered}
$$

(5) Geometric limits:

$$
\begin{aligned}
& g_{9}= \begin{cases}1.2 & \text { if } 3 t_{f}>h \\
0 & \text { Otherwise }\end{cases} \\
& g_{10}= \begin{cases}1.2 & \text { if } t_{w}>t_{f} \\
0 & \text { Otherwise }\end{cases}
\end{aligned}
$$


The notations are standard for the Eurocodes, where the same notation is used for both shear capacity and shear buckling capacity. The constraints for ultimate limit state design are $g_{1}$ to $g_{6}$ while the serviceability limit state design constraints are $g_{7}$ and $g_{8}$. Constraint $g_{1}$ is for shear capacity; $g_{2}$ is for shear buckling; $g_{3}$ is for axial capacity; $g_{4}$ is for combined axial and bending capacity; $g_{5}$ and $g_{6}$ are interaction of axial force and bending moment on buckling for major axis; and $g_{7}$ and $g_{8}$ are for horizontal and vertical deflection limits. $\delta_{e}$ and $\delta_{a}$ are deflections at eaves and apex, respectively. The superscript $u$ indicates the maximum permissible deflection. If the geometrical cross-section constraints $g_{9}$ and $g_{10}$ are exceeded, an arbitrary (lowest tier) unity factor of 1.2 is assigned. These are verified throughout the frame and are further denoted to show the maximum value within a given zone: $g_{x C}$ within the column; $g_{x R}$ within the rafter; $g_{x H}$ within the haunch. Second order effects are not accounted for in the scope of this paper as McKinstray [33] demonstrated that second order effects are insignificant due to deflection limits controlling the design resulting in low axial forces and therefore small second order effects [34].

\subsection{Optimisation methodology}

The design optimisation considered in this paper contains mixed discrete and continuous design variables. This was implemented using a genetic algorithm within the optimisation toolbox in MATLAB, i.e., using standard routines. In order to consider discrete and continuous design variables, special crossover and mutation functions enforce variables to be integers [35]. It has been observed that using the real coded genetic algorithms, large population sizes are needed in order to obtain the optimum solution consistently [36]. To help improve computational efficiency and reliability, solution space reduction and enhanced exploration based on larger initial populations, respectively, are employed here as in [2].

The three GA configurations are shown in Figure 1 and Table 9; $\mathrm{C} 1$ rolled frame optimisation (6 variables), C2 fabricated frame (12 variables) and C3 tapered frame (15 variables). To allow for asymmetry and for the increased loading on the PV side, the left and right sides of the frames were able to vary independently. Otherwise the optimisation is similar to [2]. The 
objective of the optimisation is to obtain the minimum weight of the primary members of the portal frame. This includes the weight of the column, rafter and haunch elements. For the haunch sections, this weight includes any wastage in material as a result of the fabrication. The haunch sections are cut within the web outside the root radius, realistically reflecting fabrication cutting conditions.

To solve the optimisation problem, a penalty was added to the achieved frame weight $F_{\text {weight }}$. Equation 9 shows the fitness function $F_{p}$ with two penalty levels. The constraint violation penalty multiplier parameter $P$ was the weight of the heaviest feasible configuration solution based on the design optimisation constraints. Thus the penalty for moderate constraint violations was $P$ while larger violations incur a much larger penalty of $10 P$ based on the maximum value $g_{M}$ of any individual unity factor [33].

$$
F_{p}= \begin{cases}F_{\text {weight }} & \text { if } g_{M} \leq 1 \\ F_{\text {weight }}+P & \text { if } 1<g_{M} \leq 1.5 \\ F_{\text {weight }}+10 P & \text { if } g_{M} \geq 1.5\end{cases}
$$

The penalty function in Equation 9 allows relatively small constraint violations to permit searches in both the feasible and infeasible regions simultaneously. This is known to improve the efficiency i.e. speed of the optimisation. It also prevents premature convergence due to excessive and rapid loss of useful genetic material carried by infeasible solutions.

Table 9 gives a summary of the GA parameters. The crossover probability was 0.8 . Intermediate crossover and adaptive feasible mutation [37] were employed along with binary tournament selection. The optimisation was conducted on a workstation (2.53 GHz CPU, 16 GB RAM). Individual fitness function evaluation calls took approximately one second for a full solution. However, much faster solutions were possible if a dimensional check was violated prior to analysis. Typical single optimisation run for C1, C2 and C3 are 20, 40 and 180 minutes respectively for $30 \mathrm{~m}$ span $6 \mathrm{~m}$ column height symmetric frame. The CPU times seem reasonable. 
The fitness function in Equation 9 combines the minimum weight and the constraint violations. Progress of the genetic algorithm is determined by the fitness function. The best solutions have the smallest constraint violations or none and the smallest weights. The search is therefore driven by all the relevant design variables including weight and all relevant design considerations i.e. Equations 1-9.

It should be noted that a minimum weight optimisation will not yield the same solution as a minimum cost optimisation. However, the cost calculations are not included in this paper, to limit the scope and the length of the paper.

\section{Reference frame optimisation}

The reference frame consists of a $30 \mathrm{~m}$ span frame with two column heights of $6 \mathrm{~m}$ and 12 m. Symmetric (apex ratio 0.5) and asymmetric (apex ratio 0.8 ) frames are considered. The frame is optimised for the range of ULS and SLS loading combinations with serviceability deflection constraints. From the optimisation the critical controlling factors in the design are identified along with the effect of different configurations on the optimum weight. For the reference frame and the 3 different GA configurations, different global population sizes were investigated using a population based on multipliers of $1,2,4,8$ and 16 times the number of decision variables with each optimisation run 20 times. The minimum weight and standard deviation for the 20 runs are recorded in Table 10.

As can be seen from Table 10, the reduction in standard deviation caused by increasing the population size has reached a point of diminishing returns. The standard deviations of the optimised weights are practically zero as shown in Table 10. In other words the GA finds optimal and near optimal solutions consistently. The population sizes used depend on the number of decision variable and multipliers of 8 to 16 were used. This is fairly typical and consistent with standard practice. Search space reduction eliminates portions of the solution space with infeasible and/or extremely expensive solutions. Finally the expanded initial population achieves much greater exploration early on in the optimisation. For faster 
optimisation the number of runs is reduced to 8 rather than 20 runs. As the study covers only a small topographical range of frame geometries it is advisable to choose conservative values as frames with significantly different topography will be governed by different factors leading to variable GA reliability and performance. Search space reduction and increased initial population strategies were employed to enhance GA reliability further in all cases [2].

\subsection{Reference frame optimisation study outline}

The reference frame was optimised under a range of loading and constraint configurations. Three sets of displacement limits were considered:

(1) none - with no SLS limits

(2) $\mathrm{SCl}$ - where the $\mathrm{SCl}$ limits are used

(3) IND - where the industry limits are used

Each frame was checked independently using ULS combinations LC1-8 and the full set of ULS combinations LC1-92. ULS combinations LC1-8 exclude the wind loading and closely resemble the previous works that excluded wind loading combinations that make up load combinations LC9-92. Additionally, the frames were considered with and without PV loading on the left (larger) side of the frame.

Table 11 shows the optimum frame weights for 144 frame configurations. Each solution is based on 8 optimisation runs with the minimum weight and standard deviation reported. It can be seen that in general terms, C1 produces the heaviest frames, C3 the lightest, and C2 in between as would be expected. In comparison to the minimum weight, the standard deviations are small for most cases, which indicates that the GA is well performing. The standard deviation in the table can be quite high for some optimisation cases, mainly on the fringes of the optimisation space (maximum column height $12 \mathrm{~m}$ ). This primarily occurred due to a single optimisation returning a local optimum weight, which would be larger than the true optimum. However due to the 8 runs the effect of this single local optimum is small. This was identified during the optimisation process and the number of runs was increased 
from 6 to 8 . The largest deviations occur in the heavier frames where a standard deviation of 10 for a $100 \mathrm{~kg} / \mathrm{m}^{2}$ frame has the same relative effect as deviation of 1 for a $10 \mathrm{~kg} / \mathrm{m}^{2}$ frame. Taking this into account the variation across the table is relatively consistent although with slightly poorer performance for $12 \mathrm{~m}$ column high frames with multiple constraints (deflection limits).

From Table 11 a comparison can be made between the weight of symmetric and asymmetric frames (Table 12). The frame weight increase caused by asymmetry is smaller than $20 \%$, i.e. not excessive. In some configurations the increase is smaller than $5 \%$. In some cases weight reductions are observed that could be attributed to either local optima or due to the change in bending moment shape allowing for lighter solutions. Due to the relatively small savings within the range of the standard deviations it is not possible to determine which is more likely.

Table 13 shows the percentage increase in frame weight after adding PV loading to the frame. Frames with no serviceability deflection limits have the highest increases in frame mass. This is due to the frame being governed primarily by bending, resulting in mass increases with any increase in loading. For frames with serviceability deflection limits in place, the impact of the PV panels is minimal in most cases and within the standard deviation of the optimum. This can be attributed to the frames being primarily governed by the SLS deflection limits and is reflected in low unity factors for bending and axial force. As the PV loading is small, only small amounts of additional deflection would be expected, resulting in very small section size increases. In some cases, small $(<2 \%)$ weight savings were observed; generally inside the standard deviation and indicative of the optimisation being relatively consistent.

For this frame configuration the weight increases going from the first 8 ULS load combinations to the full set are shown in Table 14. The largest weight increase can be seen in frames without deflection control. This indicates that these frames are heavily controlled 
by the wind loading, with frames with higher column heights having significantly large mass increases. For frames with deflection controls, in all cases the weight increases are relatively small (up to 10\%). From Figure 4, the column top moment increases from the gravity load combination to the full (92) ULS load combinations. For example, the moment increase ratio is 1.2 and 1.8 for the $6 \mathrm{~m}$ and $12 \mathrm{~m}$ column heights frames, respectively. This indicates that in this case the frame is mostly controlled by the serviceability deflection limits with the additional bending moments added by the wind loading not affecting the final weight, even with a significant 1.8 times increase in maximum column top moment.

\subsection{Optimisation frame profile comparison}

In conventional design, it is common practice to develop designs initially based on the gravity load combination of the frame. Based on the bending moment diagram of the gravity load combination, the frame is arranged into a series of elements, with additional steel in the form of haunches or taper elements in the eaves where the moments are highest. It has been shown previously that the inclusion of the wind adds a significant number of additional bending moment diagrams that can have control over different parts of the structure. Additionally, the displacement limits have been shown to be very influential in the selection of section profiles controlling the design of the frames. For the reference frame with PV loading, the frame profile is drawn for frames with $\mathrm{SCl}$ and without displacement limits (Figure 5). The bending moment profile envelopes of all the ULS combinations are shown on top of the frame profile to scale.

It can be seen that without SLS combinations the GA is producing generally conventional frame shapes that to a good extent follow the bending moment shape. The addition of the SLS combinations generally increases the size of the haunches without changing the overall frame shape or configuration. The only exception is found in asymmetric frames where the shorter rafter may deviate from the bending moment gradient. 
The fully tapered framed shape (Figure 1c) has been significantly reconfigured by the GA towards a more conventional haunched profile with only very minor taper to the rafter mid span. This is attributable to the bending moment envelope being significantly different from the idealised UDL gravity load combination that the shape is based upon. Unlike the more traditional hatched portal frame, the tapered frame shape is unable to accommodate the multiple moment diagrams created by different load combinations.

\section{Parametric study}

\subsection{Configuration}

In the previous section a single frame was investigated over a range of loading and serviceability deflection limits. In this section, the weight across the range of standard portal topographical configurations (spans/column heights) is optimised. Spans considered in the study range from $14.5 \mathrm{~m}$ to $50 \mathrm{~m}$; column heights range from $4 \mathrm{~m}$ to $11.5 \mathrm{~m}$ using S355 steel. The pitch and frame spacing for all frames are $10^{\circ}$ and $6 \mathrm{~m}$ (used in typical structures), respectively, resulting in a grid of $13 \times 6$ data points (highlighted in the contour plots by dots). Both symmetric and asymmetric (0.8 apex ratio) frames are considered separately using $\mathrm{C} 1, \mathrm{C} 2$ and $\mathrm{C} 3$ configurations. The optimum designs for the frames in this section are obtained by running 8 optimisations per data point. For each combination, the minimum weight was obtained (in terms of $\mathrm{kg} / \mathrm{m}^{2}$ ) and reported within contours.

\subsection{Initial study with SCI serviceability deflection limits}

Using the $\mathrm{SCl}$ serviceability deflection limits the optimised results for both symmetric and asymmetric frames are presented in Figure 6 for rolled, fabricated, and tapered frames. It is immediately clear that the profile of the contours differs significantly from those previously reported by Phan et al. [8] and McKinstray et al. [2] where a monotonic trend was observed. Excluding the wind load combinations, the same monotonic trend is found as in the literature when using S355 steel (see Figure 7). This indicates that the wind load combinations have 
a significant influence over the design resulting in heavier frames, in some cases. It should be noted that the previous comparisons both used S275 steel and in Phan et al. [8] case only rolled sections were considered. Figure 8 shows typical optimisation histories, for symmetric $30 \mathrm{~m}$ span $6 \mathrm{~m}$ column height frames, to illustrate the progress of the optimisation. The figure shows the number of function evaluations in each case.

A comparison between the optimisation solutions for different frame types is presented in Figure 9. As would be expected, the rolled sections $(\mathrm{C} 1)$ produce the heaviest frames requiring the same weight for shorter span, shorter column height structures. For an equal weight a larger structure could be designed using fabricated (C2) and even more so tapered (C3) compared to rolled (C1) design. The new contour shape for frame resembles an 'L'. For the part parallel to the span axis the variation in weight between the methods is relatively constant. However, for heavier frames, significantly larger savings are shown on the $L$ leg. This is an indication of the increased benefit of tapered frames in these situations over the other configurations.

Figure 10 shows the weight reduction moving from rolled to fabricated, fabricated to tapered and the overall reduction from rolled to tapered as a histogram of percentage reduction in weight calculated from Figure 6. In general terms, tapered frames produce the lightest results, followed by fabricated and then rolled frames. For symmetric frames the largest savings on average $(9 \%)$ are seen in moving from rolled to fabricated frames, with only a $2 \%$ further reduction going from fabricated to tapered frames. For asymmetric frames the reduction in optimum weight moving from rolled to fabricated sections is smaller $(6 \%)$ with a much larger reduction (10\%) going from fabricated to tapered. For symmetric frames the additional effort in the design and manufacturing of tapered frames is hard to justify due to the small additional weight saving over fabricated frames. However, for asymmetric frames, tapered frames have a significant benefit, with fabricated frames only having a small weight reduction and the largest weight saving achieved through tapered geometry. 


\subsection{Effect of Asymmetry}

Asymmetry does not change the overall trend or shape of the optimum contours (Figure 6). It does however change the optimum weight. Figure 11 shows symmetric contours for $\mathrm{C} 1,2$ and 3 overlapped with their asymmetric counterparts and histogram analysis of the weight change. Asymmetry adds weight to the frame on average $9 \%$ for rolled frames, $13 \%$ for fabricated frames and $5 \%$ for tapered frames. The maximum weight increase observed was $35 \%$, found in both fabricated and rolled frames.

The largest increases in frame weight can be seen from the overlapping contours to occur in long span frames with short column. This is attributed to SLS lateral displacement control of the frames, for which a symmetric configuration can resist lateral deflection (especially to short column) more effectively than the asymmetric one. Also, for long span and short column, the moment difference at the critical section for asymmetric frames is larger than in symmetric one. Fully tapered frames show much better adaptability to asymmetry than their rolled and fabricated counterparts. The asymmetry contours can be seen to follow the symmetric counterpart much closer including in the long span short column height scenarios.

The rolled and fabricated histograms could be described as skewed towards $5-10 \%$; in contrast the tapered frame has a more normal distribution around the same range. This results in a number of topographies having no weight increase with a small number $(<5 \%)$ having a weight reduction for the tapered frame.

\subsection{Importance of the wind pressure}

It has previously been shown that wind has a significant influence on the resulting contour plot shape. However, this particular case examined Belfast, an area of the UK with relatively harsh wind weather conditions. For the design proposed, wind speeds for the UK are obtained from the National Annex of Eurocode 1 part 1-4 [38]. Belfast has an equivalent wind speed of the Scottish lowlands. England has significantly lower wind speeds. Due to the nature of the wind code it is possible to scale the wind loadings to obtain different 
locations allowing for a fast rerunning of the optimisation without additional programming. This was done for Liverpool (wind speed $23 \mathrm{~m} / \mathrm{s}$, peak velocity pressure $1.0 \mathrm{kN} / \mathrm{m}^{2}$ ) and Birmingham $\left(21.75 \mathrm{~m} / \mathrm{s}\right.$ and $\left.0.787 \mathrm{kN} / \mathrm{m}^{2}\right)$. The study was limited to $\mathrm{C} 2$ fabricated beams, with $\mathrm{SCl}$ deflection limits for both symmetric ( 0.5 apex ratio) and asymmetric ( 0.8 apex ratio) frames.

Comparing the no wind case to the 3 chosen locations for symmetric frames, Figure 12 plots the percentage difference of the no wind case (Figure 7). In contrast to the reference frame, wind can be seen to clearly dominate the design with its influences being very dependent on the topographical configuration of the building. It is clear that for all Belfast and Liverpool span/column height configurations, wind dominates the design adding at least $20 \%$ and $5 \%$ to the design weights, respectively. Both locations have a large flat area with the minimum percentage influence mainly for short column height building or for taller buildings with long spans. Outside of this area there are significant weight increases based on the column height to span ratio. Birmingham is the exception where the flat area is not dominated by the influence of wind. However, like the other locations outside of this area wind dominates the frame. Plotting the diagonal of the 3 locations (red dashed line) it can be seen that there is a close relationship between the different locations, with higher wind load linearly increasing the weight of the frame with similar exponential increases in frame weight based on column high to span ratio.

The contours of frame weight for symmetric and asymmetric frames are shown in Figure 13 and Figure 14, respectively, together with histograms showing the percentage change in weights compared to Belfast. It can be seen that the symmetric and asymmetric contour plots follow each other well for each of the locations. By comparing the percentage variation between each location and Belfast, a nearly normal distribution can be seen in each case. This indicates that the weight difference between locations can be scaled, allowing for the approximate calculation of optimum weights for any part of the UK (providing the scale factor is known). 


\subsection{Effect of serviceability deflection limits}

For the three geographical locations the frames were re-optimised using the Industrial deflection limits (Section 2.4). The frame weights in comparison to the $\mathrm{SCl}$ weight are shown for Belfast in Figure 15, Liverpool in Figure 16 and Birmingham in Figure 17. A similar $L$ shaped contour plot pattern is observed in the frames with industrial deflection limits as observed with SCl limits. For all locations a small area of frames with short column height coupled with short spans were unaffected by the industrial deflection limits. Outside of this configuration, using industrial limits can lead to weight saving of up to $40 \%$.

The largest savings were found in frames with very tall column heights. For typical span to column height ratio frames, saving of $15-30 \%$ primary member weight are realistically achievable.

\section{Conclusion}

A structural design optimisation has been carried out to allow for asymmetry and fully tapered portal frames. Universal beam sections, fabricated sections and tapered frames were considered. Tapered frames were shown to produce the lightest solution followed by fabricated and then rolled frames. However, for symmetric frames the weight savings are small, with tapered frames only having a slight weight advantage over fabricated frames. As a fabricated design is cheaper to implement, due to easier design and manufacturing, tapered frames would struggle to be economically viable. For asymmetric frames the opposite is true, with the largest weight saving found using tapered geometry and only minor weight saving with fabricated sections. This makes tapered frames a much more viable design solution. It was found that multiple load cases must be considered for the design of tapered frames, particularly at the point of contraflexure where the additional bending moments from the additional load combinations are accounted for in the design verification. The traditional tapered frame shape is based on a single load combination (the gravity load 
combination); however, the optimised results show little resemblance favouring a more uniform profile with a slight taper.

In frames with $\mathrm{SCl}$ or industrial deflection limits, the addition of PV panels was shown to have a minimal impact on the optimum weight. In contrast, wind has been shown to have a significant influence on the resulting frame and should be included in the optimisation in order to produce the most realistic results for design purposes. Wind increased bending moment in frames (in some cases, very significantly), resulting in very different weight contour profiles. The contour profiles were in stark contrast to gravity load combination contours moving from a well-documented monotonic trend to an $\mathrm{L}$ shaped profile with a significant horizontal weight profile. Weight increases were largest for Belfast with the highest wind speed, and lowest for Birmingham with the slowest wind speed. For all locations short column short span frames have a plateau area where the weight increases due to wind is constant. For Birmingham no weight increases were observed in this area $(0 \%)$, Liverpool $5 \%$ and Belfast $20 \%$. Outside of the area there is large increase in weight. It was found that the optimal weight between the locations scaled well, indicating that weight could be interpolated based on site wind speed, as based on the presented results.

Asymmetric frames weighed more than their geometrically similar symmetric counterparts. Tapered frames had the smallest average weight increase of $5 \%$, with fabricated sections $13 \%$ and rolled sections $9 \%$. Tapered frame weight increases were also more consistent, with a maximum increase of $15 \%$, whereas for fabricated and rolled sections this could be as high as $40 \%$.

The chosen set of serviceability deflection limits has a significant impact on the frame weight, with up to $40 \%$ saving achieved using the industrial serviceability deflection limits compared to the $\mathrm{SCl}$ recommended limits. The weight saving is independent of the site wind speed: with the three locations having similar contours with savings based on the topographical configuration of the building. No savings were observed for very short column 
height and span buildings, with the largest saving in very tall, but not necessarily long span buildings.

\section{References}

[1] R. McKinstray, J. B. P. Lim, T. T. Tanyimboh, D. T. Phan, W. Sha, and A. E. I. Brownlee, "Topographical optimisation of single-storey non-domestic steel framed buildings using photovoltaic panels for net-zero carbon impact," Build. Environ., vol. 86, pp. 120-131, 2015.

[2] R. McKinstray, J. B. P. Lim, T. T. Tanyimboh, D. T. Phan, and W. Sha, "Optimal design of long-span steel portal frames using fabricated beams," J. Constr. Steel Res., vol. 104, pp. 104 $114,2015$.

[3] H. Saffari, R. Rahgozar, and R. Jahanshahi, "An efficient method for computation of effective length factor of columns in a steel gabled frame with tapered members," J. Constr. Steel Res., vol. 64, no. 4, pp. 400-406, Apr. 2008.

[4] M. Saka, "Optimum design of steel frames with tapered members," Comput. Struct., vol. 63, no. 4, pp. 798-811, 1997.

[5] D. Fraser, "Design of tapered member portal frames," J. Constr. Steel Res., vol. 3, no. 1, pp. 20-26, 1983.

[6] Tata Steel, Steel building design: design data. The Steel Construction Institute and The British Constructional Steelwork Association Limited, 2011.

[7] Steel Construction Institute, "SCI advisory desk AD 090: deflection limits for pitched roof portal frames (amended)," 2010.

[8] D. T. Phan, J. B. P. Lim, T. T. Tanyimboh, R. M. Lawson, Y. Xu, S. Martin, and W. Sha, "Effect of serviceability limits on optimal design of steel portal frames," J. Constr. Steel Res., vol. 86, pp. 74-84, Jul. 2013.

[9] P. R. Salter, A. S. Malik, and C. M. King, Design of single-span steel portal frames to BS 5950-1:2000 (P252). Berkshire: The Steel Construction Institute, 2004.

[10] J. M. Davies and B. A. Brown, Plastic design to BS 5950. Berkshire: Steel Construction Institute, 1996.

[11] J. B. P. Lim and D. A. Nethercot, "Serviceability design of a cold-formed steel portal frame having semi-rigid joints," Steel Compos. Struct., vol. 3, pp. 451-474, 2003. 
[12] D. M. Koschmidder and D. G. Brown, Elastic design of single-span steel portal frame buildings to Eurocode 3 (P397). Berkshire: The Steel Construction Institute, 2012.

[13] S. K. Azad and O. Hasançebi, "Discrete sizing optimization of steel trusses under multiple displacement constraints and load cases using guided stochastic search technique," Adv. Eng. Softw., vol. 52, no. 2, pp. 383-404, 2015.

[14] British Standards, BS EN 1991-1-1:2002; Eurocode 1: Actions on structures; Part 1-1: General actions - Densities, self-weight, imposed loads for buildings. London, UK, 2002.

[15] British Standards, BS EN 1990:2002; Eurocode: Basis of structural design (incorporating corrigendum December 2008 and April 2010). London, UK, 2002.

[16] British Standards, BS EN 1991-1-3:2003; Eurocode 1: Actions on structures. General actions Snow loads (incorporating corrigenda December 2004 and March 2009). London, UK, 2003.

[17] British Standards, NA to BS EN 1991-1-3:2003 National Annex to Eurocode 1: Actions on structures. General actions - Snow loads (incorporating corrigendum no. 1, June 2007). London, UK, 2005.

[18] British Standards, NA to BS EN 1991-1-1:2002; UK National Annex to Eurocode 1: Actions on structures. General actions - Densities, self-weight, imposed loads for buildings. London, UK, 2005.

[19] British Standards, BS EN 1991-1-4:2005; Eurocode 1: Actions on structures Part 1-4: General actions Wind actions. London, UK, 2005.

[20] British Standards, BS EN 1993-1-1:2005; Eurocode 3: Design of steel structures Part 1-1: General rules and rules for buildings. London, UK, 2005.

[21] British Standards, NA to BS EN 1993-1-1: UK national annex to Eurocode 3: Design of steel structures. London, UK, 2005.

[22] British Standards, BS EN 10034:1993; Structural steel I and H sections tolerances on shape and dimensions. London, UK, 1993.

[23] Standards New Zealand, NZS 3404; Steel structures standard; Both parts supersede NZS 3404: Parts 1 and 2. New Zealand, 1997.

[24] M. Bradford and P. Cuk, "Elastic buckling of tapered monosymmetric I-beams," ASCE J. Struct. Eng, vol. 114, no. 5, pp. 977-996, 1988.

[25] V. Šapalas, M. Samofalov, and V. Šaraškinas, "FEM stability analysis of tapered beam columns," J. Civ. Eng. Manag., vol. 11, no. 3, pp. 211-216, Jan. 2005. 
[26] L. Zhang and G. S. Tong, "Lateral buckling of web-tapered I-beams: A new theory," J. Constr. Steel Res., vol. 64, no. 12, pp. 1379-1393, Dec. 2008.

[27] L. R. S. Marques, "Tapered steel members: flexural and lateral-torsional buckling," PhD thesis, Universidade de Coimbra, 2012.

[28] S. K. Azad and O. Hasançebi, "Computationally efficient discrete sizing of steel frames via guided stochastic search heuristic," Comput. Struct., vol. 156, pp. 12-28, Aug. 2015.

[29] M. R. Maheri and M. M. Narimani, "An enhanced harmony search algorithm for optimum design of side sway steel frames," Comput. Struct, vol. 140, pp. 55-65, 2014.

[30] F. Flager, G. Soremekun, A. Adya, J. Kristina Shea, O. Haymaker, and M. Fischer, "Fully constrained design: A general and scalable method for discrete member sizing optimization of steel truss structures," Comput. Struct., vol. 140, pp. 55-65, Jul. 2014.

[31] J. Leng, Z. Li, J. K. Guest, and B. W. Schafer, "Shape optimization of cold-formed steel columns with fabrication and geometric end-use constraints," Thin-Walled Struct., vol. 85, pp. 271-290, 2014.

[32] M. Moharrami, A. Louhghalam, and M. Tootkabon, "Optimal folding of cold formed steel cross sections under compression,” Thin-Walled Struct., vol. 76, pp. 145-156, 2014.

[33] R. Mckinstray, "Single storey steel building optimisation for steel weight and carbon incorporating asymmetric topology with photovoltaic panels," $\mathrm{PhD}$ thesis, Queen's Univeristy Belfast, 2015.

[34] J. B. P. Lim, C. M. King, A. J. Rathbone, J. M. Davies, and V. Edmonson, "Eurocode 3 and the in-plane stability of portal frames," Struct. Eng., vol. 83, no. 21, pp. 43-49, 2005.

[35] K. Deep, K. P. Singh, M. L. Kansal, and C. Mohan, "A real coded genetic algorithm for solving integer and mixed integer optimization problems," Appl. Math. Comput., vol. 212, no. 2, pp. 505-518, Jun. 2009.

[36] D. T. Phan, J. B. P. Lim, W. Sha, C. Y. M. Siew, T. T. Tanyimboh, H. K. Issa, and F. A. Mohammad, "Design optimization of cold-formed steel portal frames taking into account the effect of building topology," Eng. Optim., vol. 45, no. 4, pp. 415-433, Apr. 2013.

[37] MathWorks, “Optimization toolbox ${ }^{\mathrm{TM}}$ user's guide.” MathWorks, Natick, 2013.

[38] British Standards, NA to BS EN 1991-1-4:2005+A1:2010UK; National Annex to Eurocode 1 Actions on structures Part 1-4: General actions - Wind actions. London, UK, 2010. 


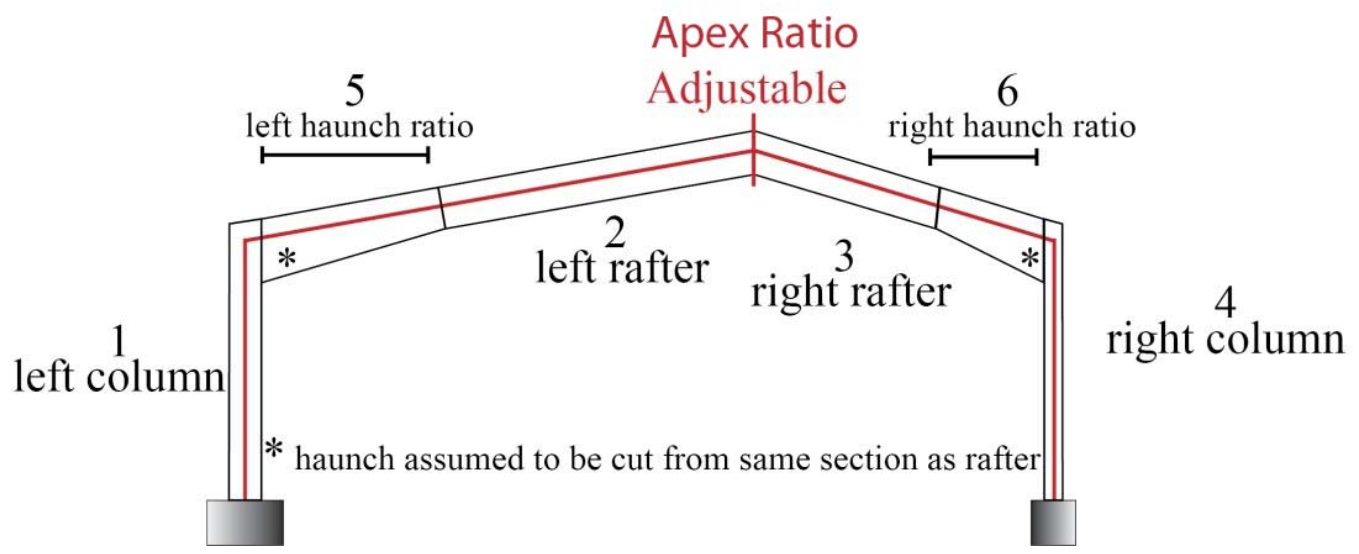

a) C1 - Rolled section decision variables

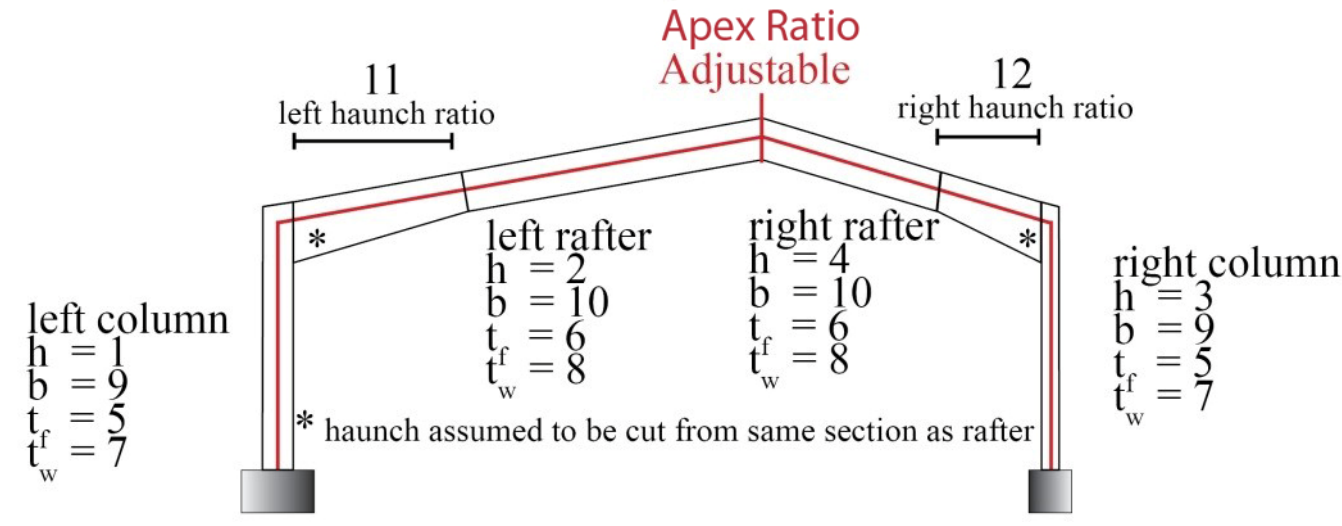

b) C2 - Fabricated frame decision variables

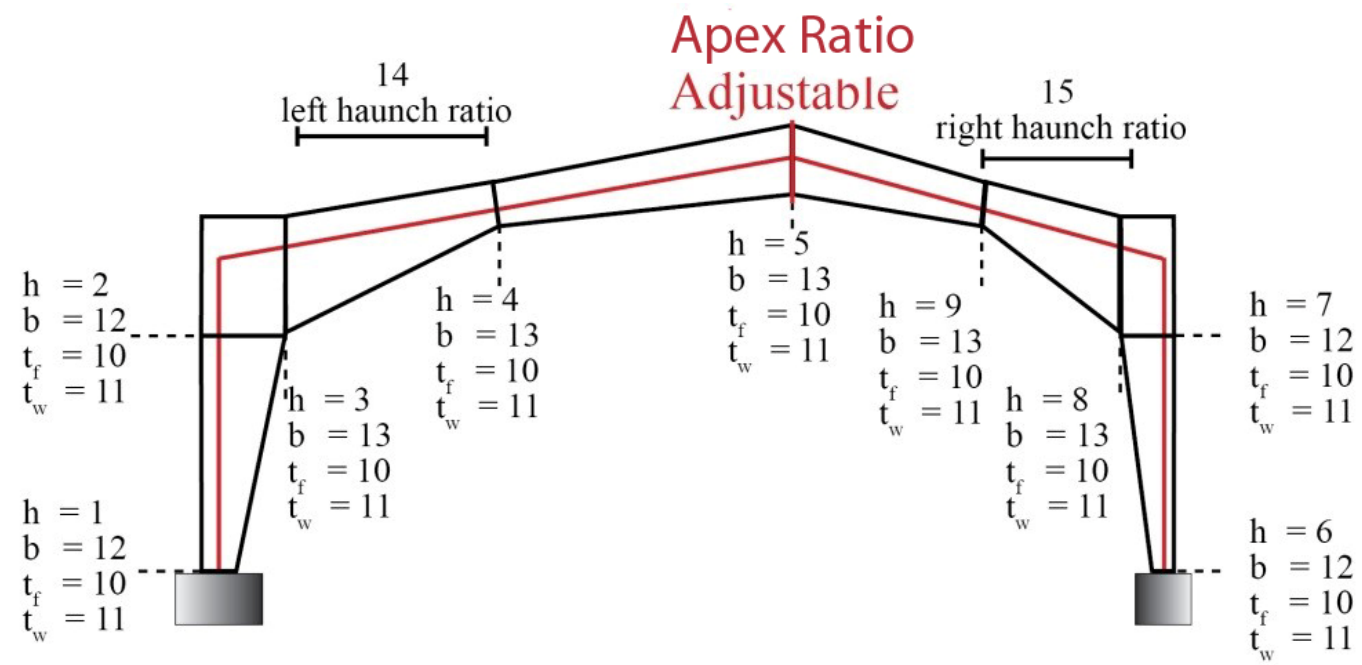

c) C3 -Tapered frame decision variables

Figure 1 Frame configurations and design variables 


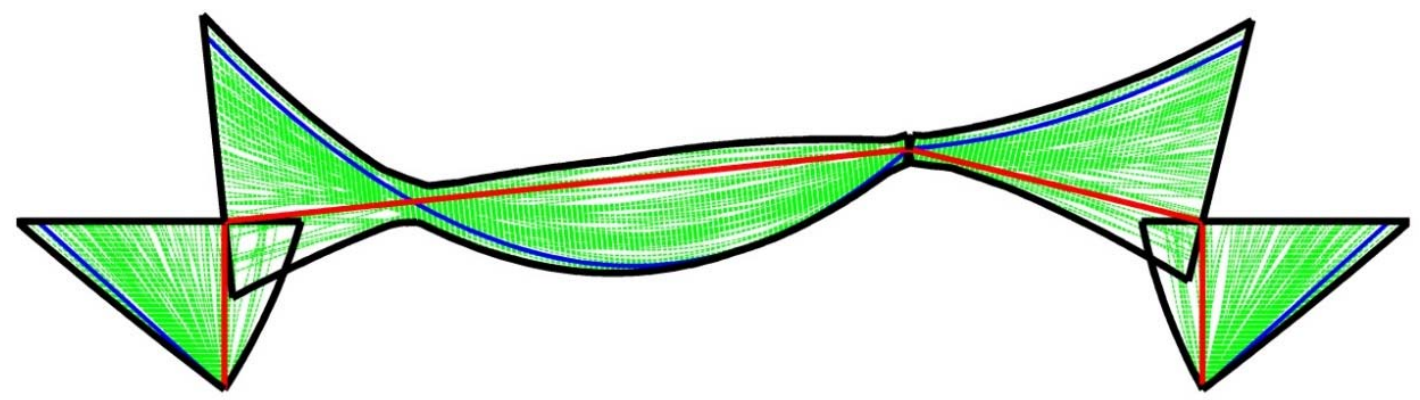

a) A low frame with gravity dominating ULS load combinations

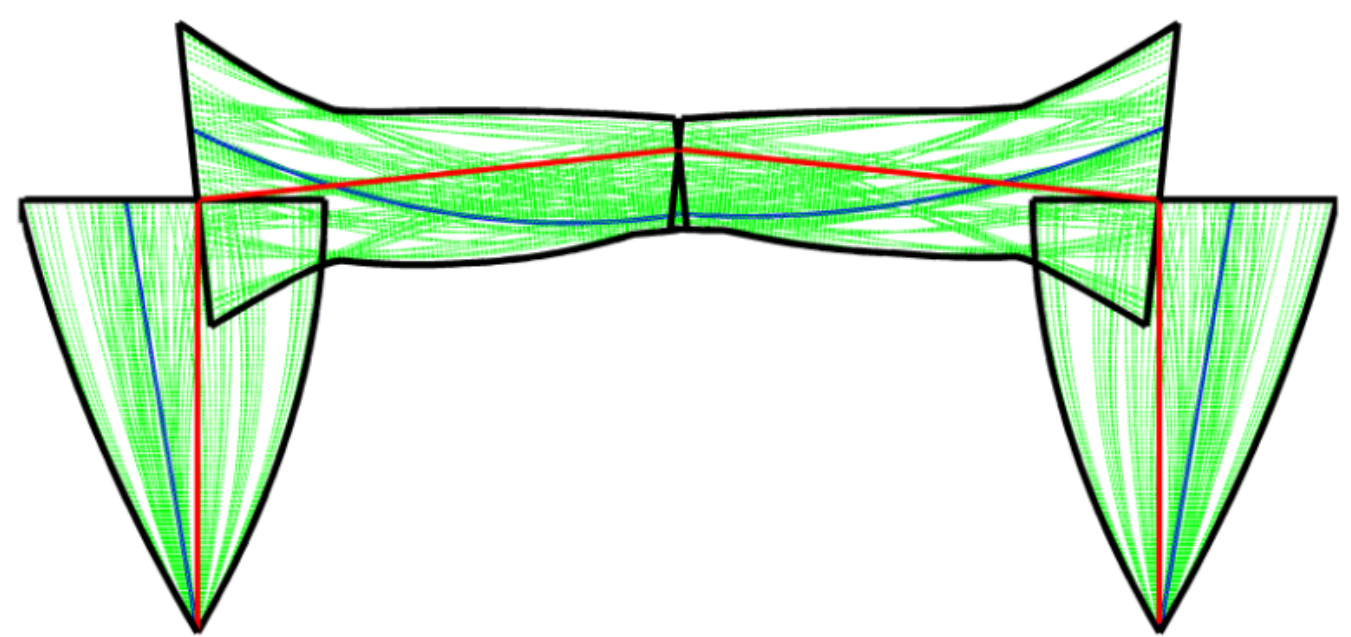

b) A tall frame with wind dominating ULS load combinations

Figure 2 Examples of all ULS load combinations moment diagrams (92 load cases).

Note: The thick black line in each diagram connects the maximum bending moment in every portal frame location, i.e., the envelope of all green and blue lines. 


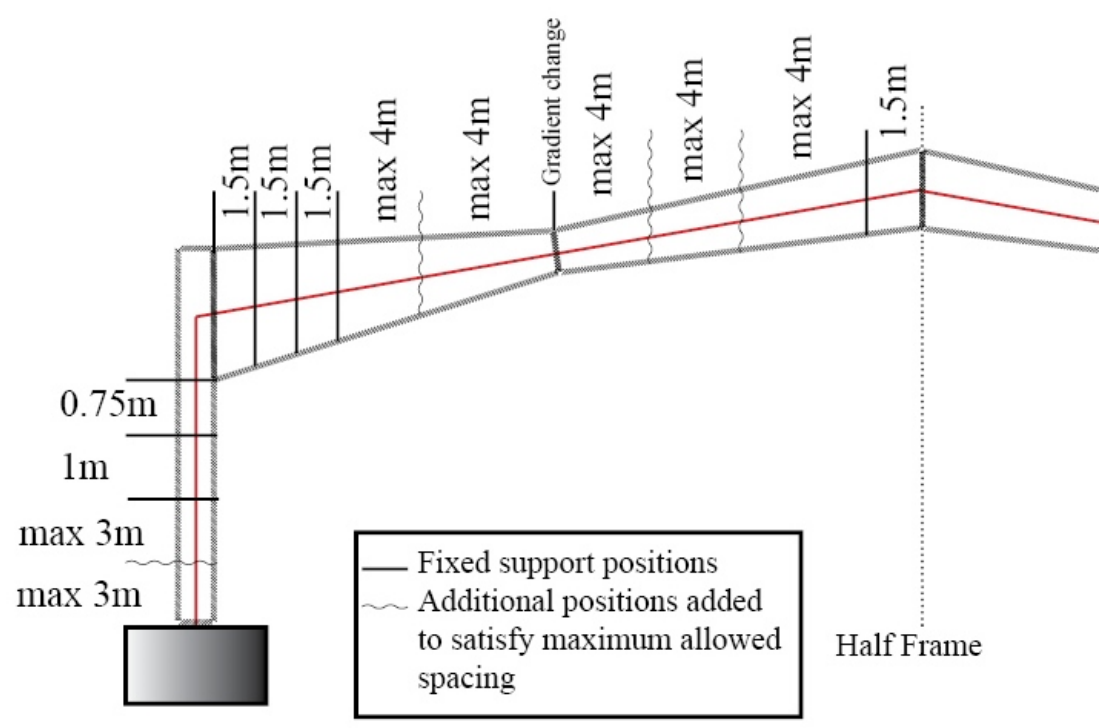

Figure 3 Frame stability verification segmentation 


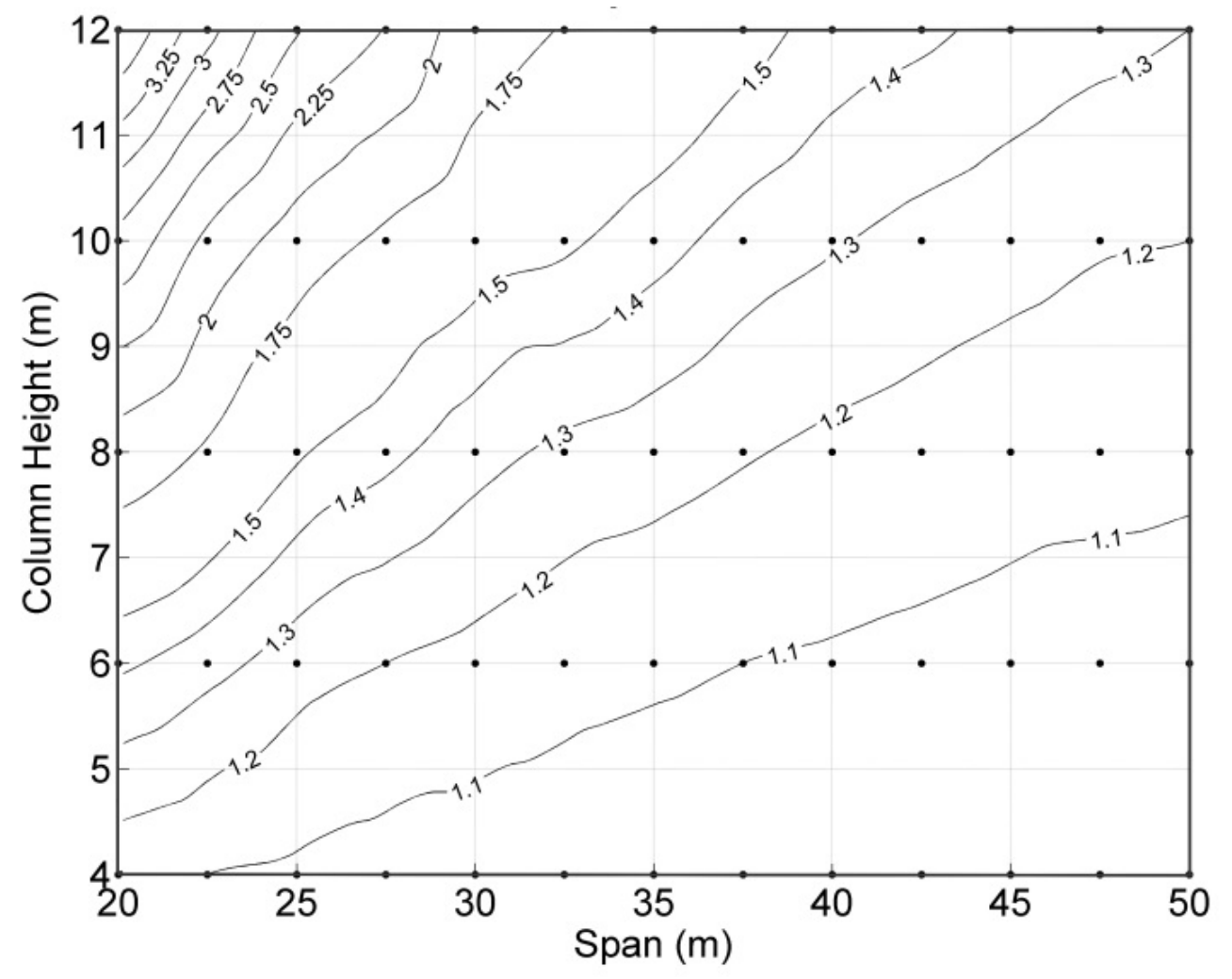

Figure 4 Ratio of column top moment between the maximum load combination (LC1-92) and gravity load combination (LC1) 


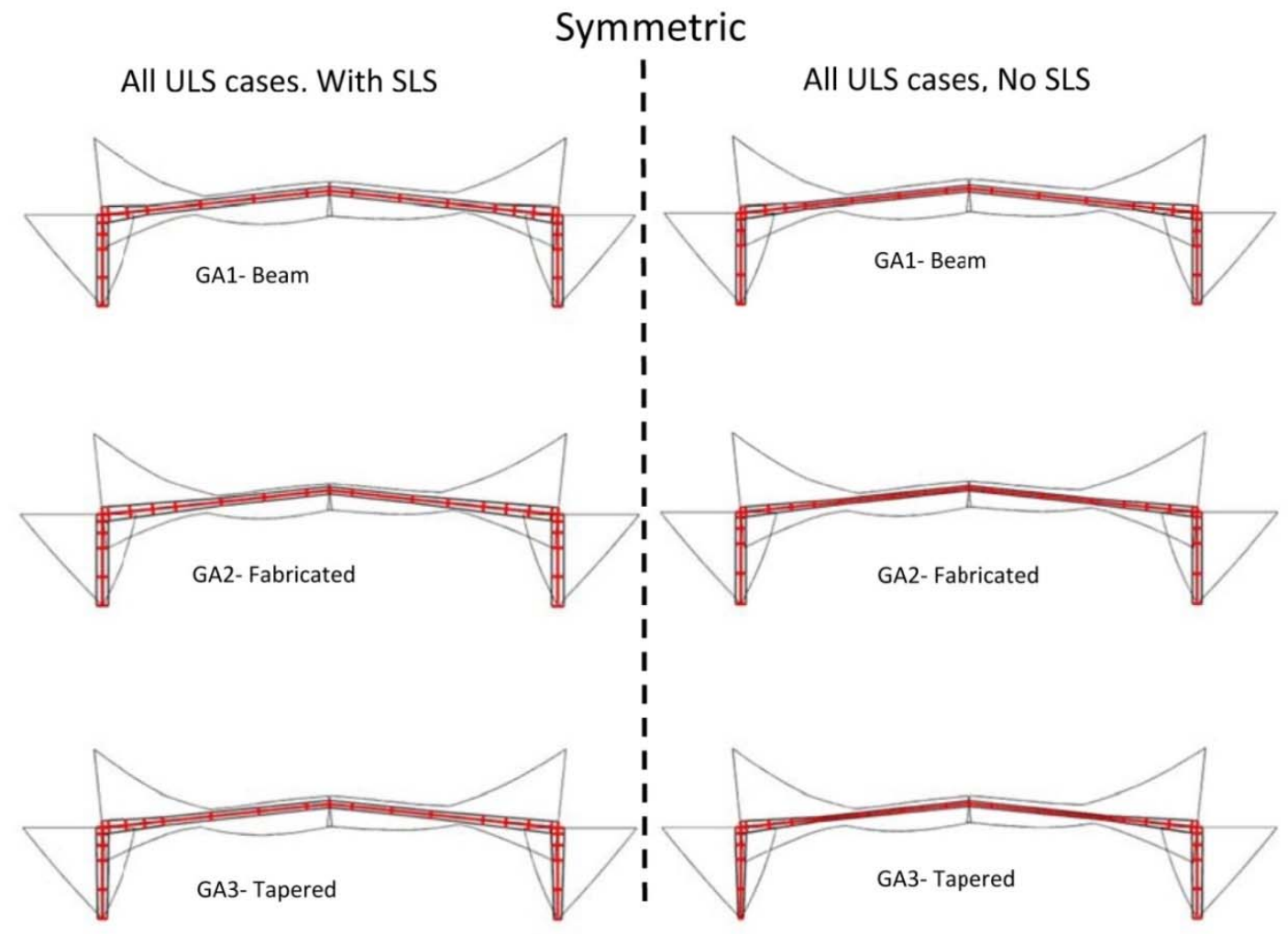

Asymmetric
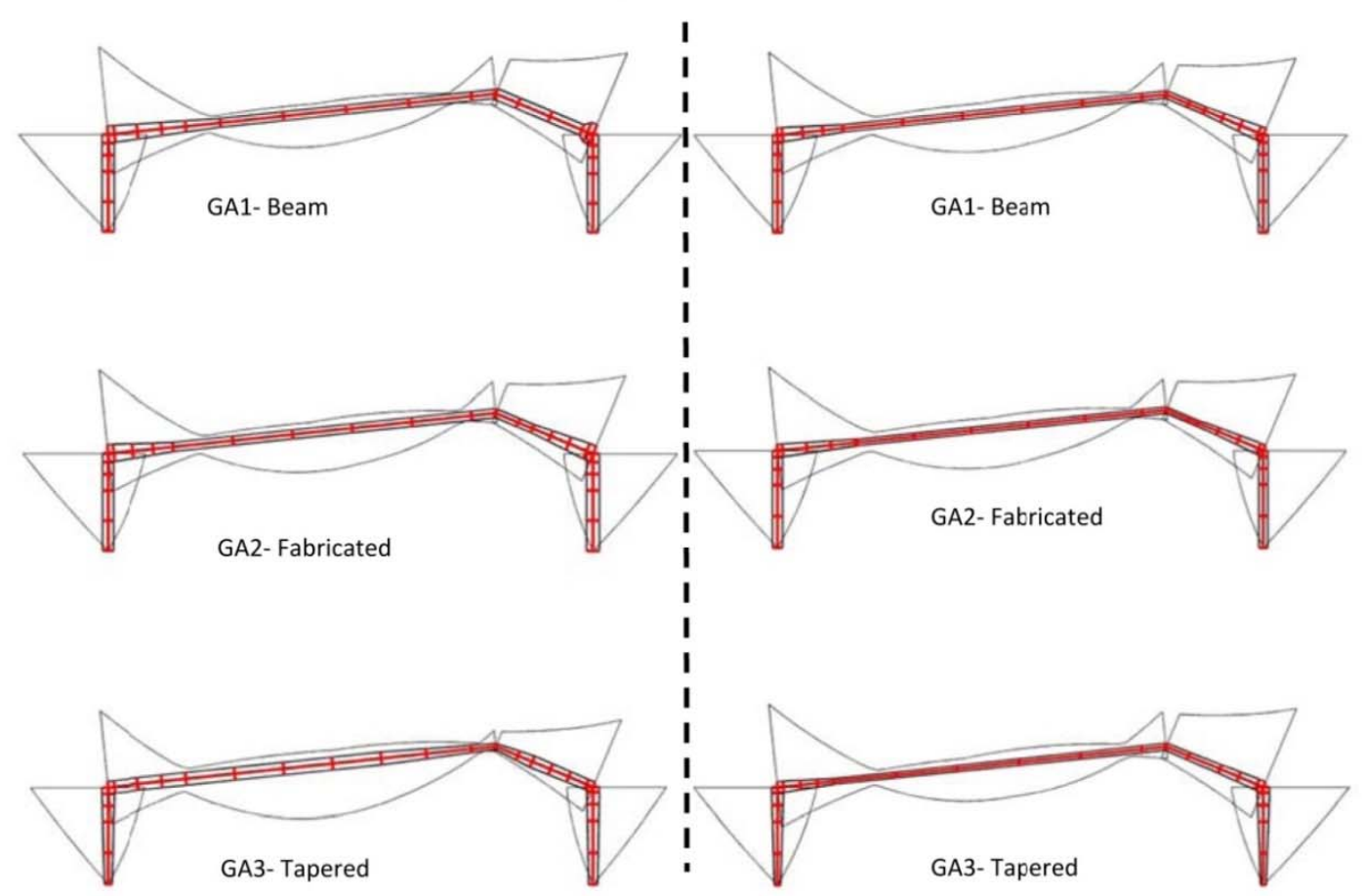

Figure 5 Optimised frame profiles 


\section{Symmetric frame Optimisation}

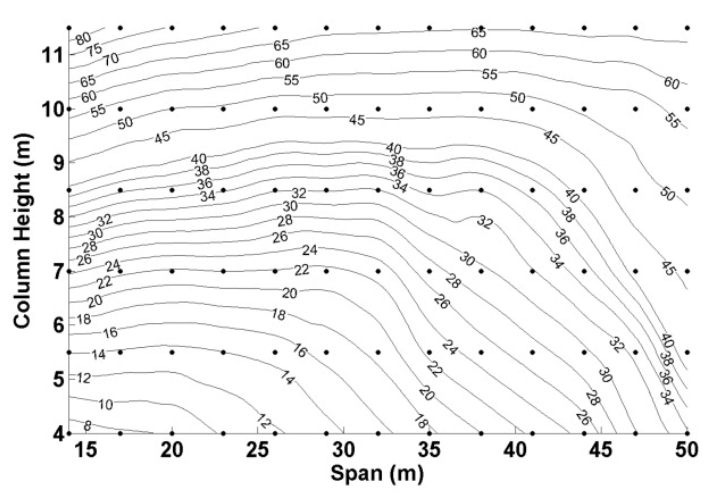

a) Rolled Optimisation frame $\mathrm{C1}$

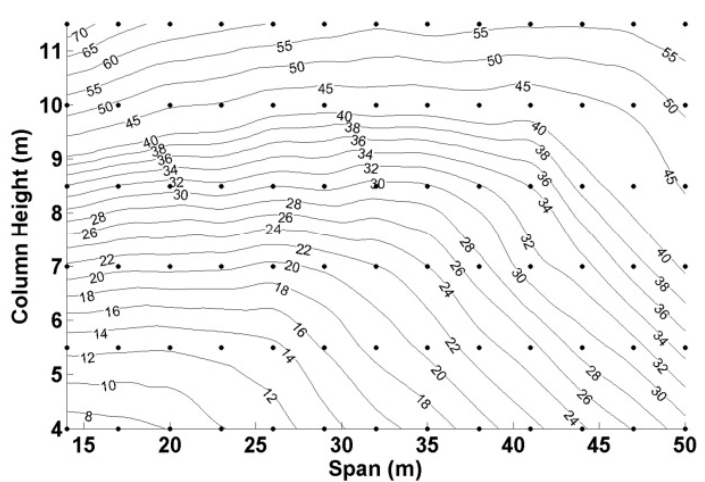

b) Fabricated Optimisation C2

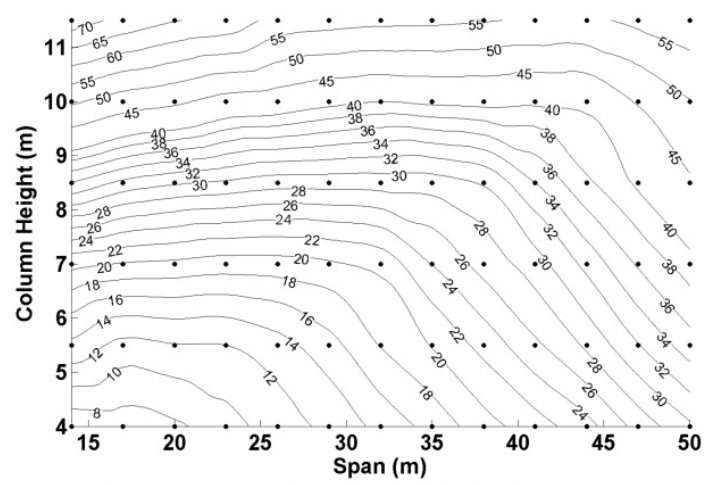

c) Tapered Frame Optimisation C3
Asymmetric frame Optimisation

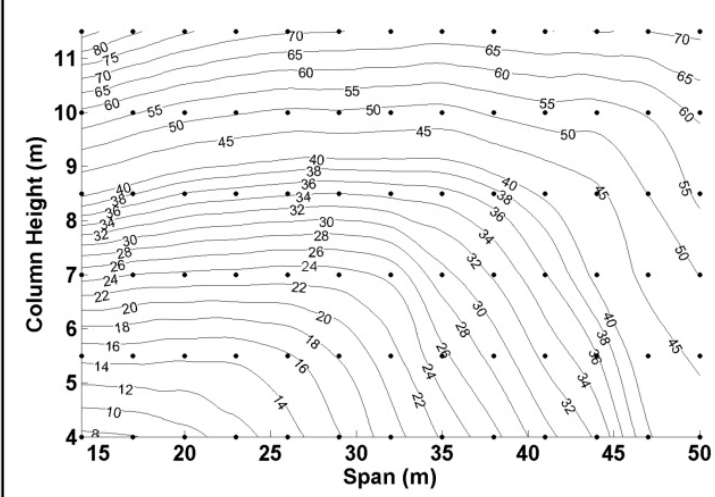

d) Rolled Optimisation frame $\mathrm{C1}$

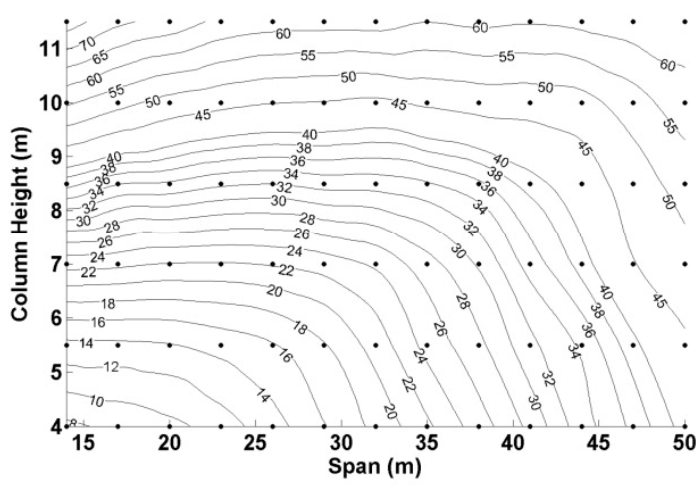

e) Fabricated Optimisation C2

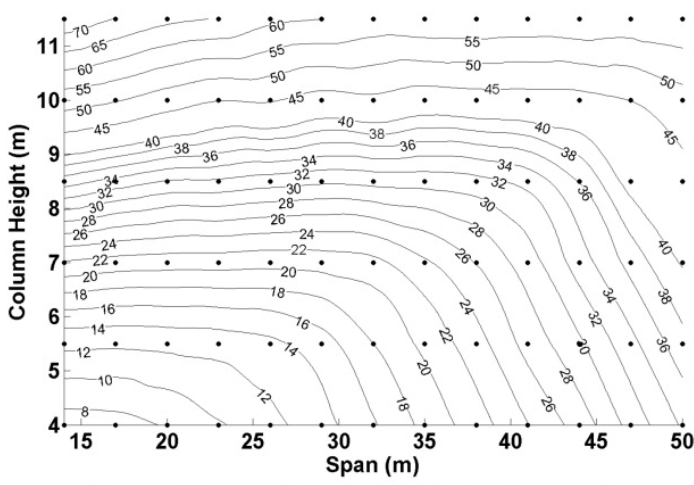

f) Tapered Frame Optimisation C3

Figure 6 Optimum frame weights $\left(\mathrm{kg} / \mathrm{m}^{2}\right)$ 


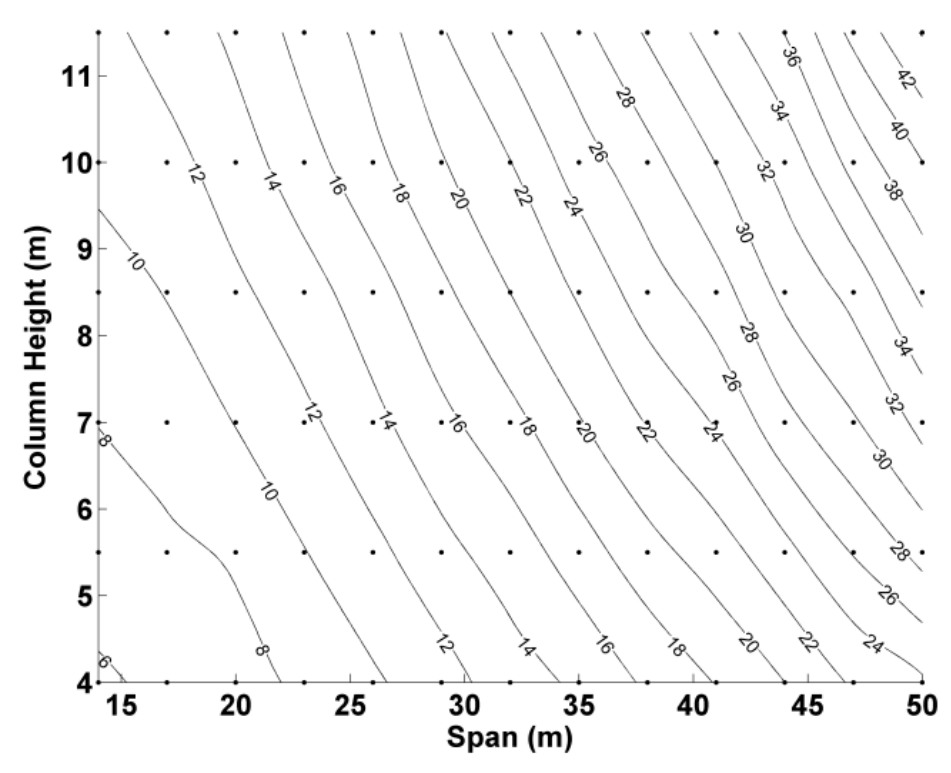

Figure 7 Contours of optimum frame weights $\left(\mathrm{kg} / \mathrm{m}^{2}\right)$, for the case of symmetric frames using fabricated sections (S355) with no wind

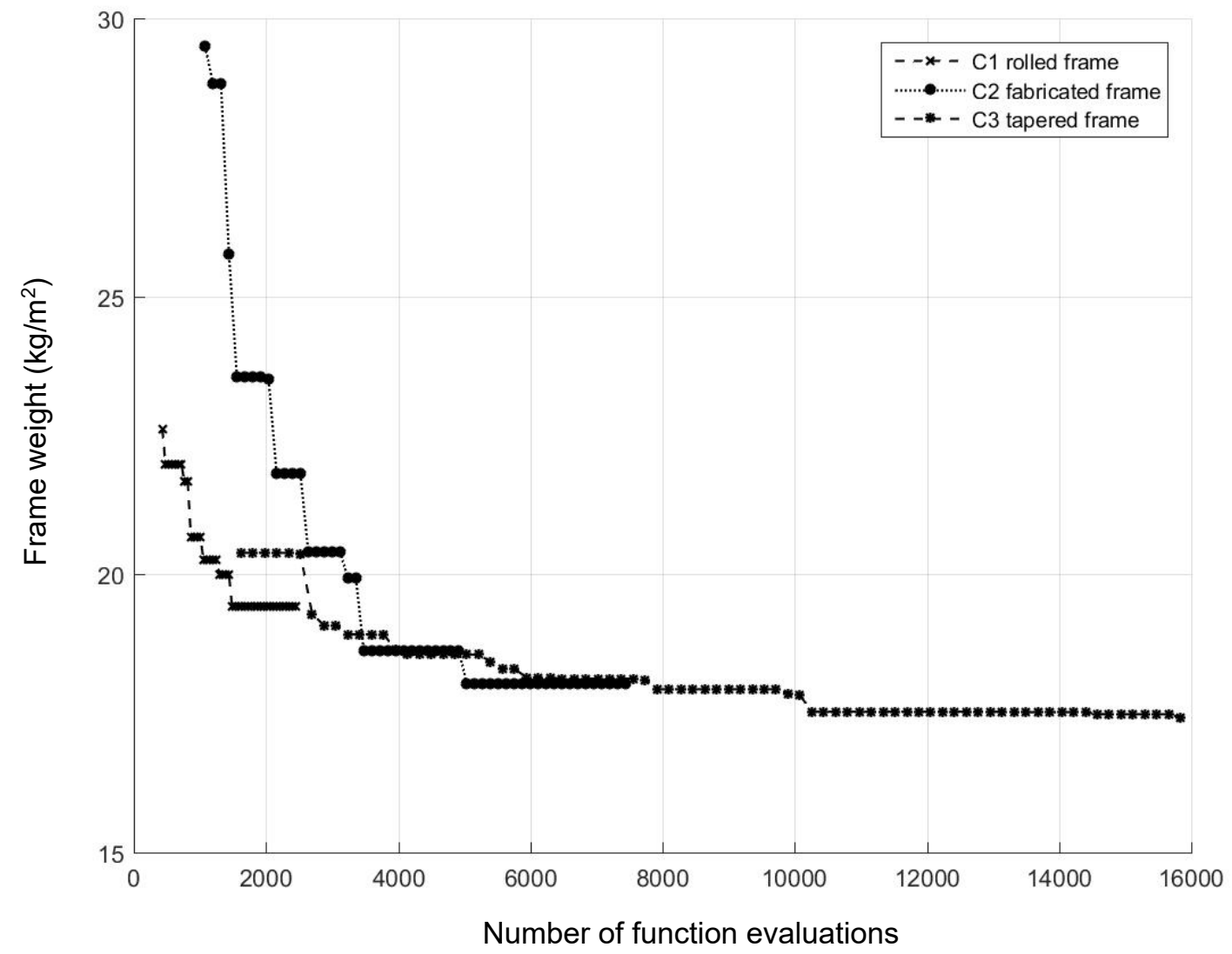

Figure 8 Optimisation history for symmetric frame having $30 \mathrm{~m}$ span and $6 \mathrm{~m}$ column height 


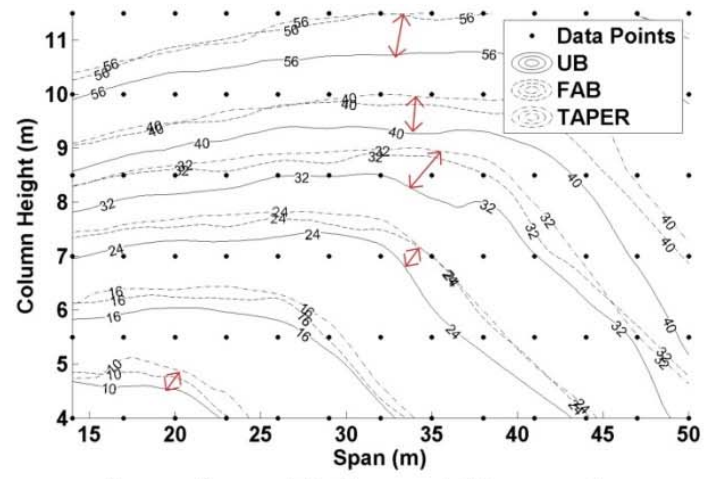

a) Symmetric frame wight comparison

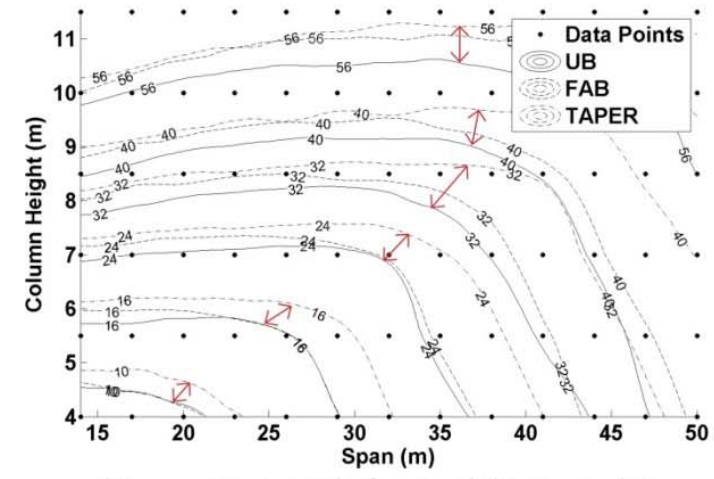

b) Asymmetric frame wight comparison

Figure 9 Contours of optimum frame weights $\left(\mathrm{kg} / \mathrm{m}^{2}\right)$, comparing rolled (UB), fabricated (FAB) and tapered (TAPER) sections
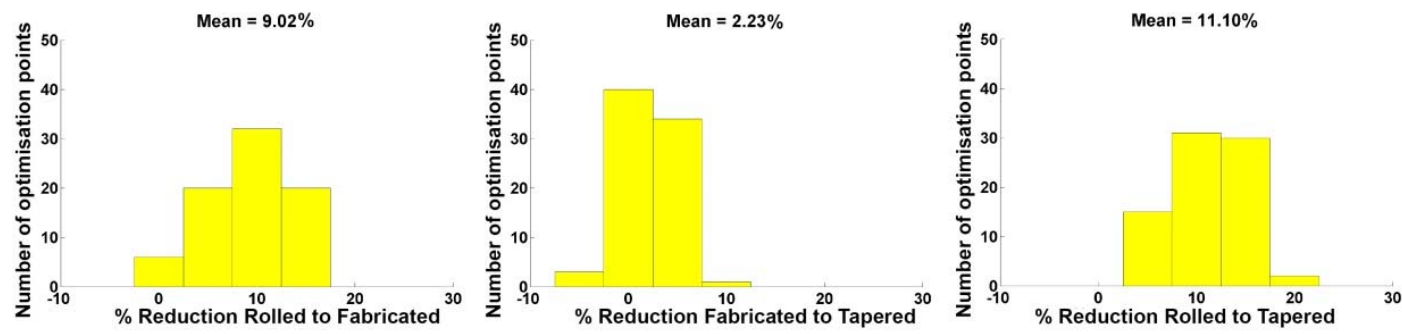

a) Symmetric
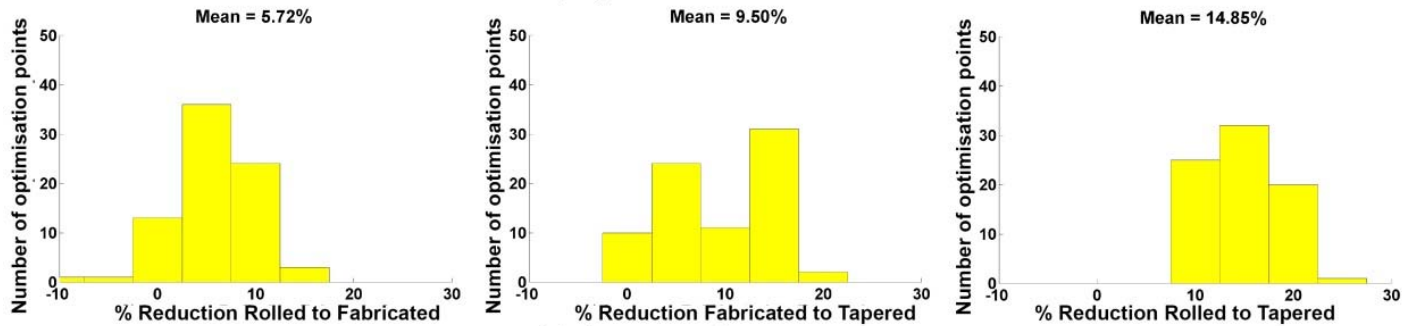

b) Asymmetric

Figure 10 Weight reduction between configurations 1, 2 and 3 


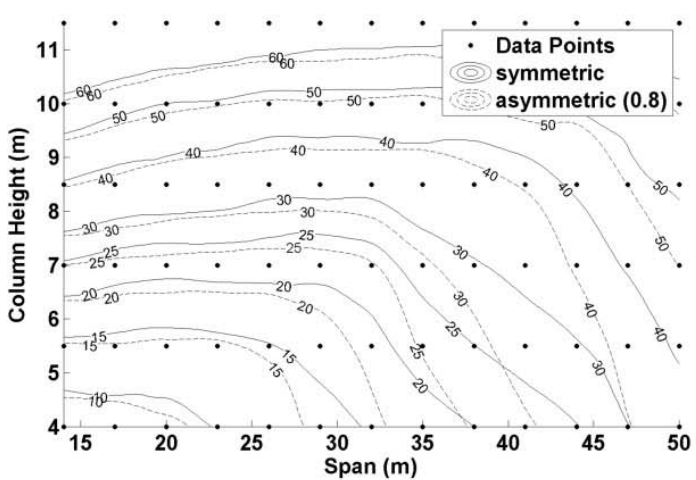

a) Rolled sections symmetric \& asymmetric

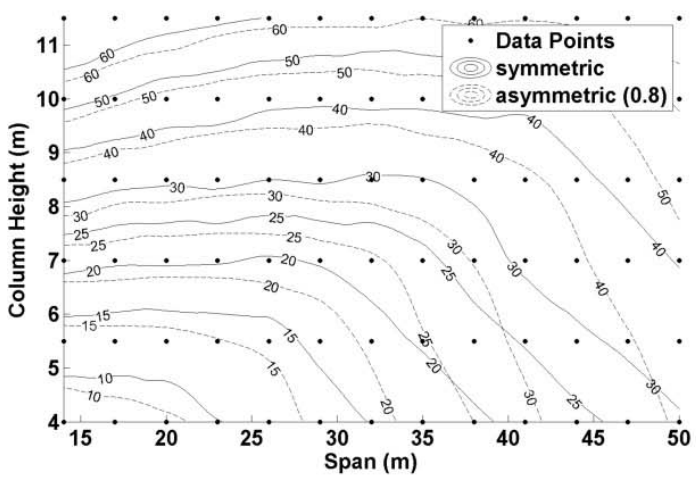

b) Fabricated sections symmetric \& asymmetric

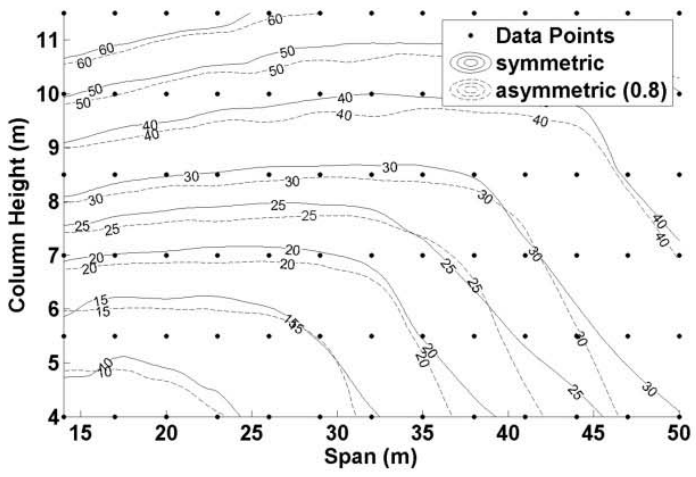

c) Tapered sections symmetric \& asymmetric

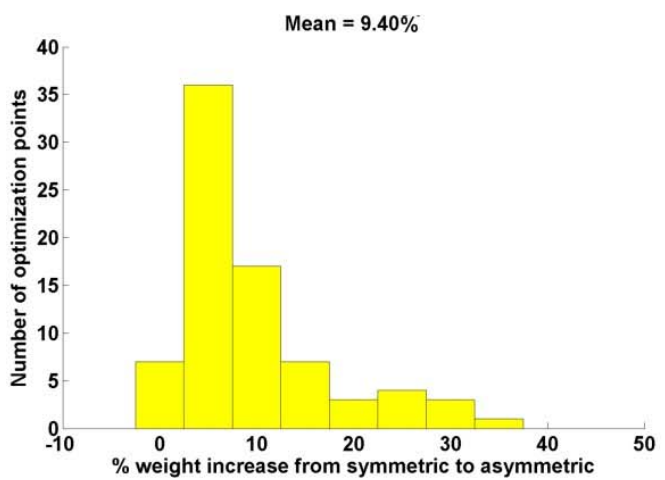

d) Rolled sections histogram

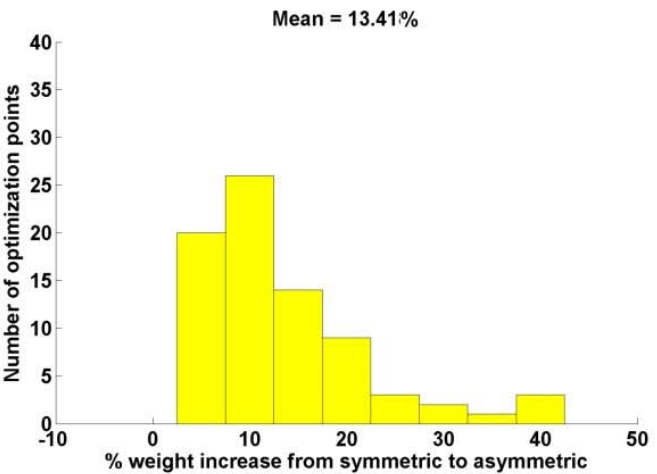

e) Fabricated sections histogram

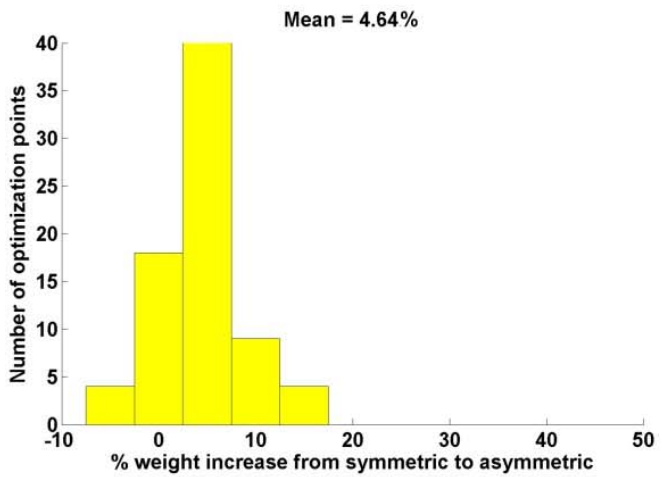

f) Tapered sections histogram

Figure 11 Contours of optimum frame weights $\left(\mathrm{kg} / \mathrm{m}^{2}\right)(\mathrm{a}, \mathrm{c}, \mathrm{e})$ and histogram analysis of the weight increase when changing from symmetric to asymmetric frames $(b, d, f)$ 


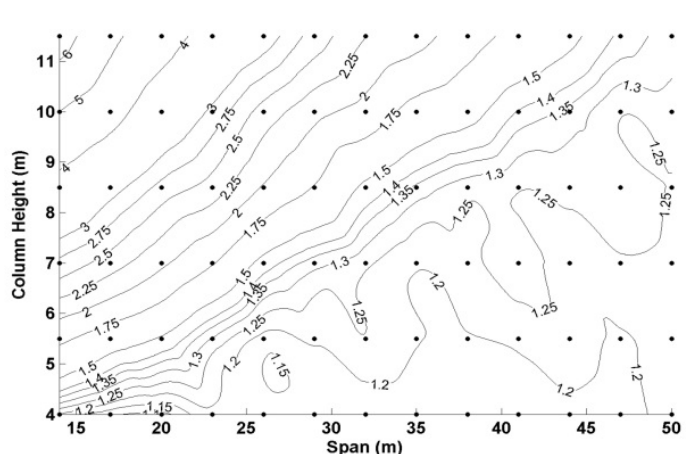

a) Ratio of Belfast wind case to no wind case

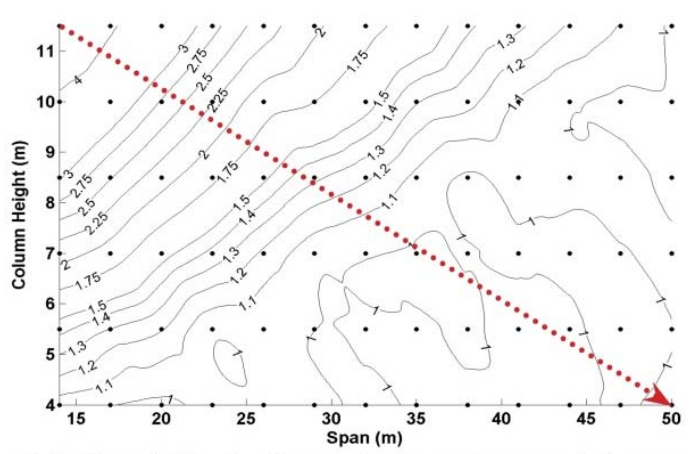

c) Ratio of Birmingham wind case to no wind case

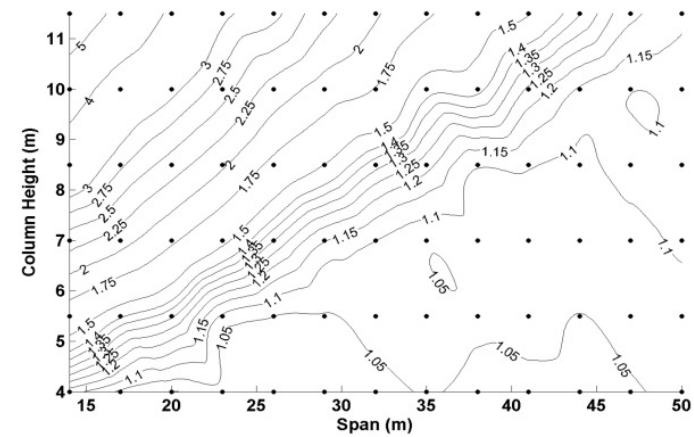

b) Ratio of Liverpool wind case to no wind case

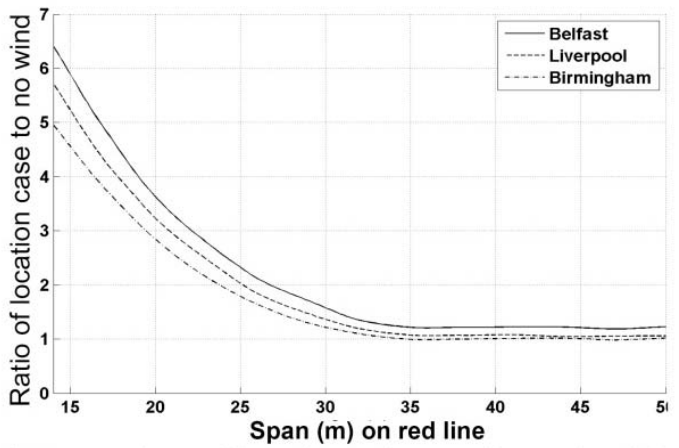

d) Comparison of location ratios on diagonal red line

Figure 12 Location optimum weight comparisons (symmetric frames) 

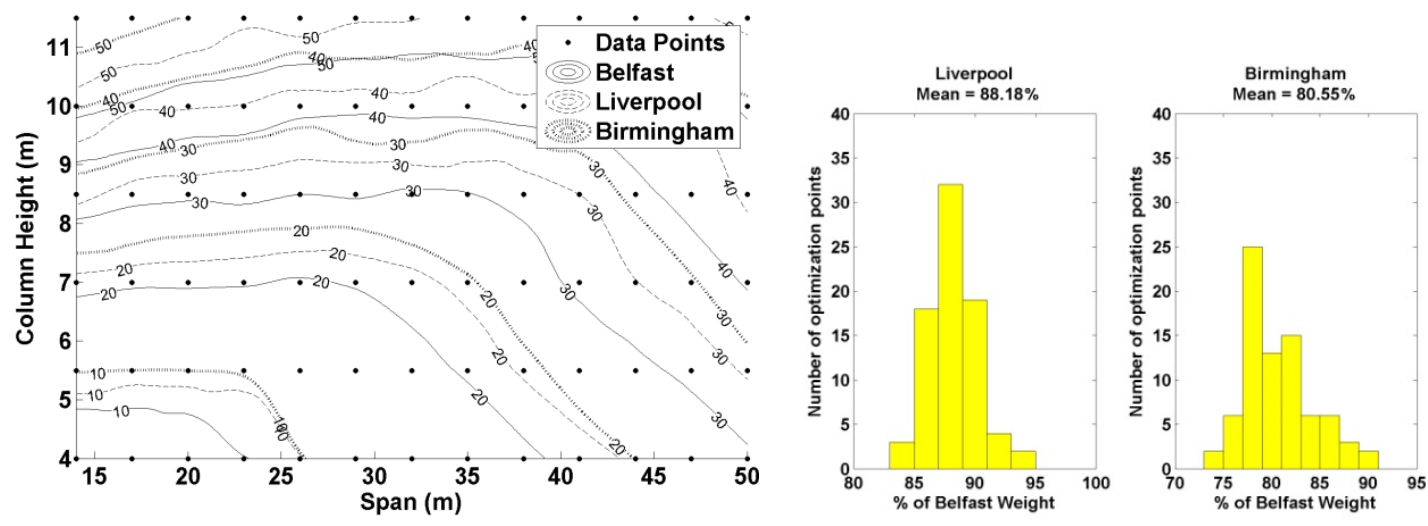

Figure 13 Contours of optimum symmetric frame weights $\left(\mathrm{kg} / \mathrm{m}^{2}\right)$ and histogram analysis of the weight decrease when changing from Belfast (high wind) to Liverpool (medium wind) and Birmingham (low wind)
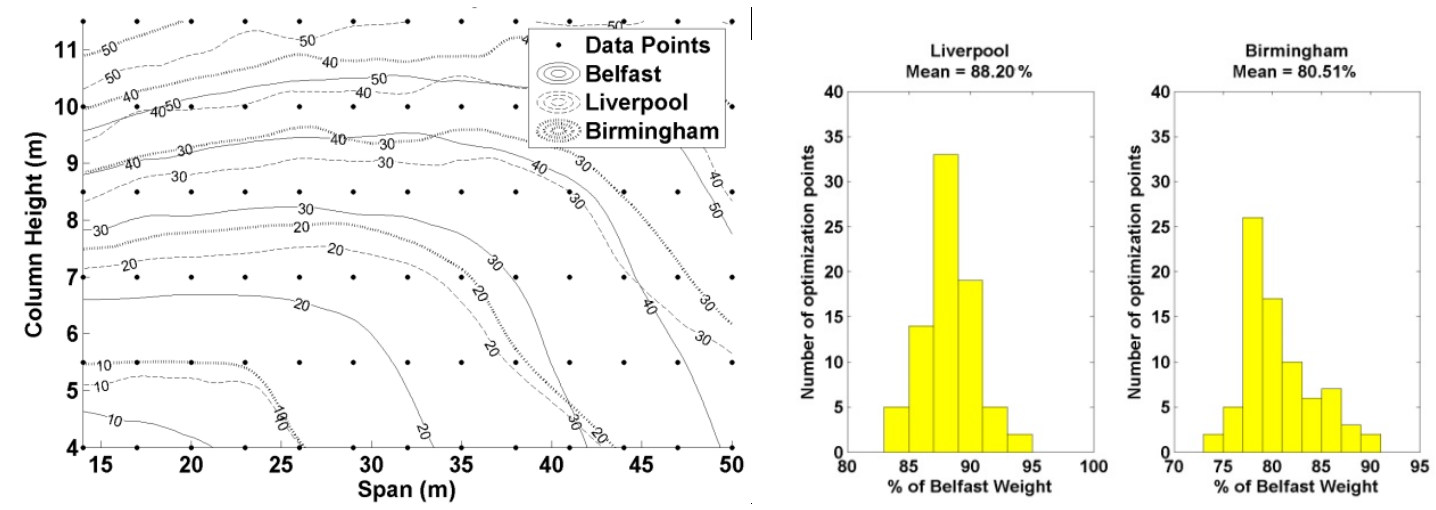

Figure 14 Contours of optimum asymmetric frame weights $\left(\mathrm{kg} / \mathrm{m}^{2}\right)$ and histogram analysis of the weight decrease when changing from Belfast (high wind) to Liverpool (medium wind) and Birmingham (low wind) 


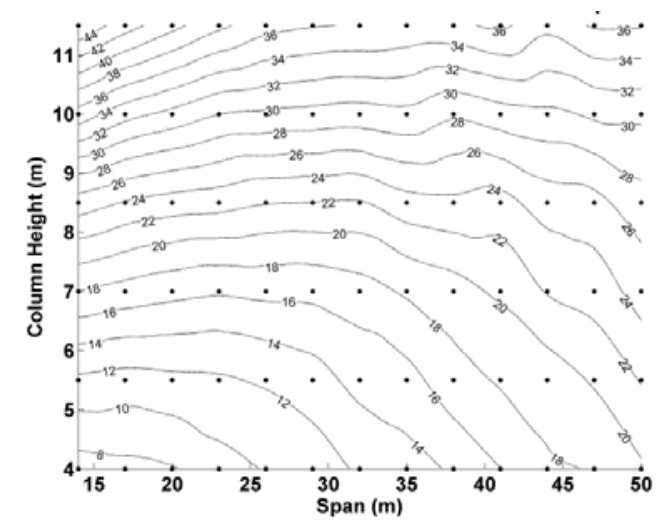

a) Belfast frame weights $\left(\mathrm{kg} / \mathrm{m}^{2}\right)$ with Industry defection limits

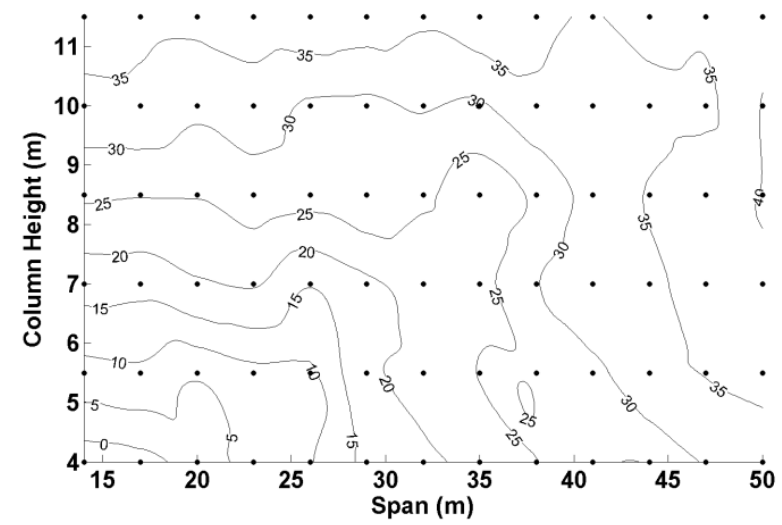

b) Percentage weight reduction with Industry defection limits compared to $\mathrm{SCl}$

Figure $15 \mathrm{SCl}$ and Industrial serviceability limits comparison Belfast

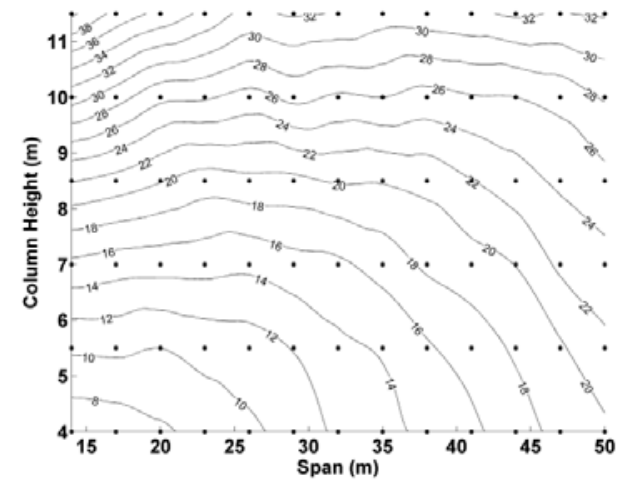

a) Liverpool frame weights $\left(\mathrm{kg} / \mathrm{m}^{2}\right)$ with Industry defection limits

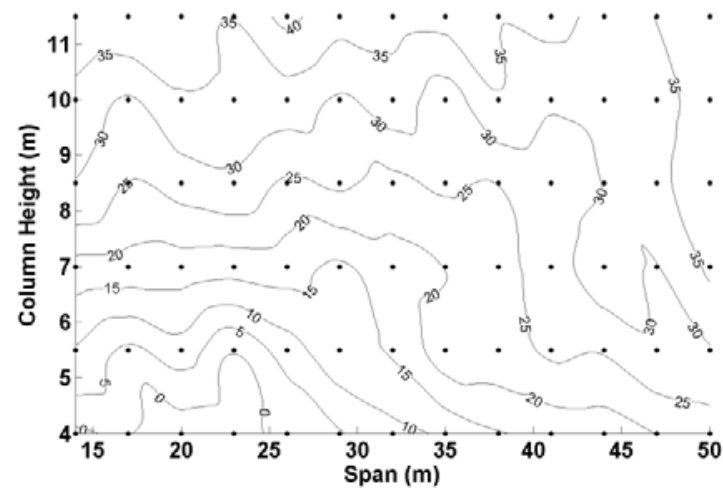

b) Percentage weight reduction with Industry defection limits compared to $\mathrm{SCl}$

Figure $16 \mathrm{SCl}$ and Industrial serviceability limits comparison Liverpool

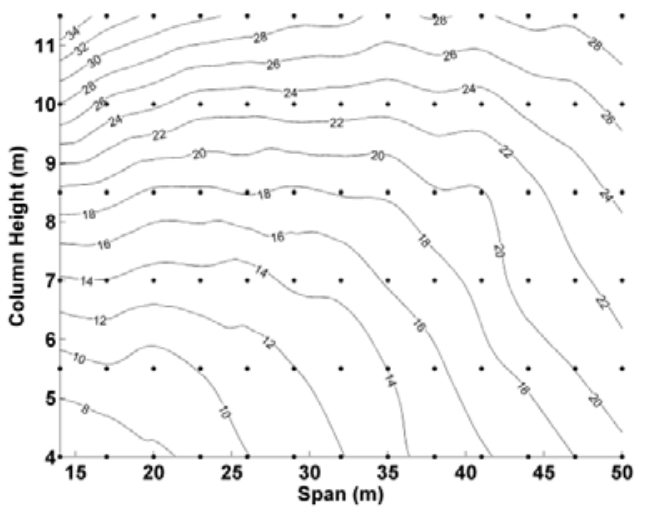

a) Birmingham frame weights $\left(\mathrm{kg} / \mathrm{m}^{2}\right)$ with Industry defection limits

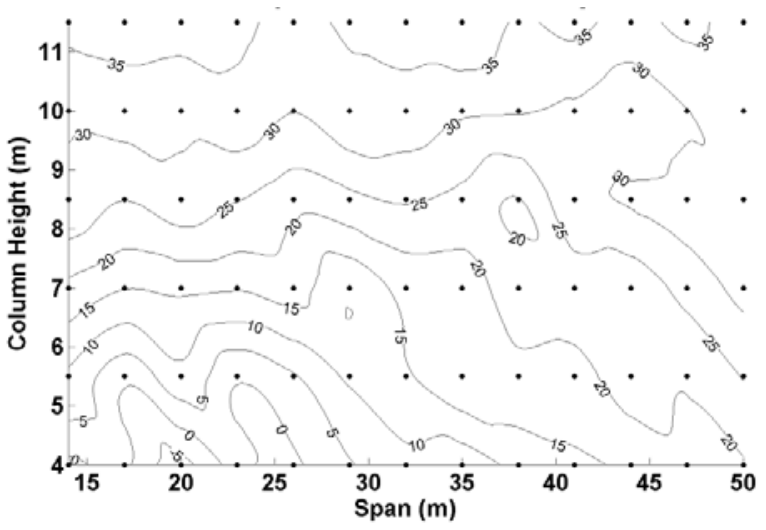

b) Percentage weight reduction with Industry defection limits compared to SCl

Figure $17 \mathrm{SCl}$ and Industrial serviceability limits comparison Birmingham 
Table 1 Wind force calculation assumptions

\begin{tabular}{|l|l|l|l|}
\hline & Belfast & Liverpool & Birmingham \\
\hline Building length (m) & 75 & 75 & 75 \\
\hline Building width & $\begin{array}{l}\text { Variable (model } \\
\text { specific) }\end{array}$ & $\begin{array}{l}\text { Variable (model } \\
\text { specific) }\end{array}$ & $\begin{array}{l}\text { Variable (model } \\
\text { specific) }\end{array}$ \\
\hline Roof type & Duopitch & Duopitch & Duopitch \\
\hline Eave height & $\begin{array}{l}\text { Variable (model } \\
\text { specific) }\end{array}$ & $\begin{array}{l}\text { Variable (model } \\
\text { specific) }\end{array}$ & $\begin{array}{l}\text { Variable (model } \\
\text { specific) }\end{array}$ \\
\hline Roof slope (degree) & 6 & 6 & 6 \\
\hline $\begin{array}{l}\text { Negative internal pressure } \\
\text { coefficient* }\end{array}$ & -0.3 & -0.3 & -0.3 \\
\hline $\begin{array}{l}\text { Positive internal pressure } \\
\text { coefficient* }\end{array}$ & 0.2 & 0.2 & 0.2 \\
\hline Wind speed (m/s) & 25.5 & 23 & 21.75 \\
\hline Site altitude (m) & 100 & 60 & 150 \\
\hline Sessional factor C season & 1.0 & 1.0 & 1.0 \\
\hline Terrain type & Country & Town & Town \\
\hline Pressure calculation method & 360 method & 360 method & 360 method \\
\hline Directions factor C dir & 1.0 & 1.0 & 1.0 \\
\hline Closest distance to sea (km) & 0 & 0 & 148 \\
\hline $\begin{array}{l}\text { Peak velocity pressure } \\
\text { (kN/m }{ }^{2} \text { ) }\end{array}$ & $\begin{array}{l}\text { Variable } \\
\text { (topography } \\
\text { specific) }\end{array}$ & $\begin{array}{l}0.755 \text { of Belfast } \\
\text { preak velocity }\end{array}$ & $\begin{array}{l}\text { pressure } \\
\text { Belfast peak } \\
\text { velocity pressure }\end{array}$ \\
\hline
\end{tabular}

*Dimensionless coefficient multiplied by the dynamic wind pressure to obtain the actual pressure for the building. 
Table 2 Design values of actions for persistent or transient design situations

\begin{tabular}{|c|c|c|c|c|}
\hline \multirow[b]{2}{*}{ Equation } & \multicolumn{2}{|c|}{ Permanent actions } & \multicolumn{2}{|c|}{ Variable actions } \\
\hline & Unfavourable & Favourable & Unfavourable & Favourable \\
\hline 6.10 & $\gamma_{G_{j}, \text { sup }} G_{k j, \text { sup }}$ & $\gamma_{G \mathrm{j}, \mathrm{inf}} \mathrm{G}_{\mathrm{kj}, \mathrm{inf}}$ & $\gamma_{Q, 1} Q_{k, 1}$ & $\gamma_{Q, i} \Psi_{0, i} Q_{k, i}$ \\
\hline $6.10 a$ & $\gamma_{G \mathrm{j}, \text { sup }} G_{\mathrm{kj}, \text { sup }}$ & $\gamma_{G \mathrm{j}, \mathrm{inf}} \mathrm{G}_{\mathrm{kj}, \mathrm{inf}}$ & $\gamma_{Q, i} \Psi_{0, i} Q_{k, i}$ & $\gamma_{Q, i} \Psi_{0, i} Q_{k, i}$ \\
\hline $6.10 \mathrm{~b}$ & $\xi \gamma \gamma_{\mathrm{G}, \text { sup }} \mathrm{G}_{\mathrm{kj}, \text { sup }}$ & $\gamma_{G \mathrm{j}, \mathrm{inf}} \mathrm{G}_{\mathrm{kj}, \mathrm{inf}}$ & $\gamma_{\mathrm{Q}, 1} \mathrm{Q}_{\mathrm{k}, 1}$ & $\gamma_{Q, i} \Psi_{0, i} Q_{k, i}$ \\
\hline
\end{tabular}

Table taken from BS EN 1990 [15], where:

$\gamma_{G \mathrm{j}, \text { sup }}=1.35$ partial factor for unfavourable permanent actions

$\gamma_{\mathrm{Gj}, \mathrm{inf}}=1.0$ partial factor for favourable permanent actions

$\gamma_{Q j, \text { sup }}=1.5$ partial factor for unfavourable variable actions

$\gamma_{\mathrm{Qj}, \mathrm{inf}}=0$ partial factor for favourable variable actions

$\Psi_{0}=0.5$ combination factor for wind and snow actions

$\Psi_{0}=0.7$ combination factor for imposed roof loads

$\xi=0.925$ 
Table 3 Symmetric factors for design combinations at ULS

\begin{tabular}{|c|c|c|c|c|c|c|c|}
\hline Actions & $\begin{array}{c}\text { Load } \\
\text { combination }\end{array}$ & Permanent & Variable & Snow & Wind & $\begin{array}{c}\text { Wind } \\
\text { uplift }\end{array}$ & $\begin{array}{c}\text { Notional } \\
\text { horizontal } \\
\text { force }\end{array}$ \\
\hline \multirow{3}{*}{$\begin{array}{c}\text { Factors for } \\
\text { combinations } \\
\text { of actions }\end{array}$} & 1 & 1.35 & 1.5 & - & - & - & Included \\
\cline { 2 - 8 } & 2 & 1.35 & - & 1.5 & - & - & Included \\
\cline { 2 - 8 } & 4 & 1.35 & - & 1.5 & $0.5 \times 1.5$ & - & - \\
\cline { 2 - 8 } & 5 & 1.35 & - & $0.5 \times 1.5$ & 1.5 & - & - \\
\hline
\end{tabular}


Table 4 Asymmetric expanded factors for design combinations at ULS

\begin{tabular}{|c|c|c|c|c|c|c|c|c|c|}
\hline \multirow{2}{*}{$\begin{array}{c}\text { Equivalent } \\
\text { LC of Table } \\
3\end{array}$} & \multirow[b]{2}{*}{ LC } & \multirow{2}{*}{$\begin{array}{l}\text { Self- } \\
\text { weight } \\
\text { steel }\end{array}$} & \multicolumn{3}{|l|}{ Left hand side } & \multicolumn{2}{|c|}{ Right hand side } & \multirow{2}{*}{$\begin{array}{l}\text { Notional } \\
\text { horizontal } \\
\text { force }\end{array}$} & \multirow[b]{2}{*}{ Wind } \\
\hline & & & PV permanent & permanent & access & permanent & access & & \\
\hline $1 \& 2$ & 1 & 1.35 & 1.35 & 1.35 & 1.5 & 1.35 & 1.5 & 0 & - \\
\hline $1 \& 2$ & 2 & 1.35 & 1.35 & 1.35 & 1.5 & 1.35 & 1.5 & 1 & - \\
\hline $1 \& 2$ & 3 & 1.35 & 1.35 & 1.35 & 1.5 & 1.35 & 1.5 & -1 & - \\
\hline $1 \& 2$ & 4 & 1.35 & 0 & 1.35 & 0 & 1.35 & 1.5 & 1 & - \\
\hline $1 \& 2$ & 5 & 1.35 & 0 & 1.35 & 1.5 & 1.35 & 0 & 1 & - \\
\hline $1 \& 2$ & 6 & 1.35 & 1.35 & 1.35 & 1.5 & 1.35 & 0 & 1 & - \\
\hline $1 \& 2$ & 7 & 1.35 & 1.35 & 1.35 & 0 & 1.35 & 1.5 & 1 & - \\
\hline $1 \& 2$ & 8 & 1.35 & 0 & 1.35 & 1.5 & 1.35 & 1.5 & 1 & - \\
\hline--- & --- & --- & --- & $\overline{---}$ & Snow & -- & Snow & --- & -- \\
\hline 3 & $9-14$ & 1.35 & 1.35 & 1.35 & 1.5 & 1.35 & 1.5 & $\mathrm{~N} / \mathrm{A}$ & $1.5 \times 0.5 \times A$ to $F$ \\
\hline 3 & $15-20$ & 1.35 & 1.35 & 1.35 & 1.5 & 1.35 & 0 & N/A & $1.5 \times 0.5 \times A$ to $F$ \\
\hline 3 & $21-26$ & 1.35 & 1.35 & 1.35 & 0 & 1.35 & 1.5 & N/A & $1.5 \times 0.5 \times A$ to $F$ \\
\hline 3 & $27-32$ & 1.35 & 0 & 1.35 & 1.5 & 1.35 & 1.5 & N/A & $1.5 \times 0.5 \times A$ to $F$ \\
\hline 3 & $33-38$ & 1.35 & 0 & 1.35 & 0 & 1.35 & 1.5 & N/A & $1.5 \times 0.5 \times A$ to $F$ \\
\hline 3 & $39-44$ & 1.35 & 0 & 1.35 & 1.5 & 1.35 & 0 & N/A & $1.5 \times 0.5 \times A$ to $F$ \\
\hline$\overline{4}$ & $45-50$ & 1.35 & 1.35 & 1.35 & $0.5 \times 1.5$ & 1.35 & $0.5 \times 1.5$ & $\mathrm{~N} / \mathrm{A}$ & $1.5 \times A$ to $F$ \\
\hline 4 & $51-56$ & 1.35 & 1.35 & 1.35 & $0.5 \times 1.5$ & 1.35 & $0.5 \times 0$ & N/A & $1.5 \times A$ to $F$ \\
\hline 4 & $57-62$ & 1.35 & 1.35 & 1.35 & $0.5 \times 0$ & 1.35 & $0.5 \times 1.5$ & $\mathrm{~N} / \mathrm{A}$ & $1.5 \times A$ to $F$ \\
\hline 4 & $63-68$ & 1.35 & 0 & 1.35 & $0.5 \times 1.5$ & \begin{tabular}{|l|}
1.35 \\
\end{tabular} & $0.5 \times 1.5$ & $\mathrm{~N} / \mathrm{A}$ & $1.5 \times A$ to $F$ \\
\hline 4 & $69-74$ & 1.35 & 0 & 1.35 & $0.5 \times 0$ & 1.35 & $0.5 \times 1.5$ & $\mathrm{~N} / \mathrm{A}$ & $1.5 \times A$ to $F$ \\
\hline 4 & $75-80$ & 1.35 & 0 & 1.35 & $0.5 \times 1.5$ & 1.35 & $0.5 \times 0$ & N/A & $1.5 \times A$ to $F$ \\
\hline 5 & $81-86$ & 1 & 1 & 1 & 0 & 1 & 0 & $N / A$ & $1.5 \times A$ to $F$ \\
\hline 5 & $87-92$ & 1 & 0 & 1 & 0 & 1 & 0 & $\mathrm{~N} / \mathrm{A}$ & $1.5 \times A$ to $F$ \\
\hline
\end{tabular}


Table 5 SLS load combinations

\begin{tabular}{|l|l|l|l|l|l|l|l|l|l|}
\hline & \multirow{2}{*}{$\begin{array}{l}\text { Load } \\
\text { combination }\end{array}$} & $\begin{array}{l}\text { Self-weight } \\
\text { steel }\end{array}$ & $\begin{array}{l}\text { PV } \\
\text { permanent }\end{array}$ & permanent & snow & permanent & snow & Wind \\
\hline $\begin{array}{l}\text { Differential } \\
\text { deflection }\end{array}$ & $1-6$ & 0 & 0 & 0 & 0 & 0 & 0 & $1 \times$ A-F \\
\hline $\begin{array}{l}\text { Differential } \\
\text { deflection }\end{array}$ & $7-12$ & 0 & 0 & 0 & 0.8 & 0 & 0.8 & $0.8 \times$ A-F \\
\hline $\begin{array}{l}\text { Differential } \\
\text { deflection }\end{array}$ & 13 & 0 & 0 & 0 & 1 & 0 & 1 & 0 \\
\hline$\ldots$ & $\ldots$ & $\ldots$ & $\ldots$ & $\ldots$ & Access & $\ldots$ & Access & $\ldots$ \\
\hline $\begin{array}{l}\text { Differential } \\
\text { deflection }\end{array}$ & 14 & 0 & 0 & 0 & 1 & 0 & 1 & 0 \\
\hline$\ldots$ & $\ldots$ & $\ldots$ & $\ldots$ & $\ldots$ & snow & $\ldots$ & snow & $\ldots$ \\
\hline $\begin{array}{l}\text { Absolute } \\
\text { deflection }\end{array}$ & $1-6$ & 1 & 1 & 1 & 0 & 1 & 0 & $1 \times$ A-F \\
\hline $\begin{array}{l}\text { Absolute } \\
\text { deflection }\end{array}$ & $7-12$ & 1 & 1 & 0.8 & 1 & 0.8 & $0.8 \times$ A-F \\
\hline $\begin{array}{l}\text { Absolute } \\
\text { deflection }\end{array}$ & 13 & $\ldots$ & 1 & 1 & 1 & 1 & 1 & 0 \\
\hline$\ldots$ & 1 & 1 & 1 & 1 & 1 & 1 & 0 \\
\hline $\begin{array}{l}\text { Absolute } \\
\text { deflection }\end{array}$ & 14 & 1 & $\ldots$ & $\ldots$ & access & $\ldots$ & access & $\ldots$ \\
\hline
\end{tabular}


Table 6 Deflection limits for profiled metal sheeting

\begin{tabular}{|c|c|c|c|c|}
\hline & $\begin{array}{c}\text { Differential lateral } \\
\text { deflection }\end{array}$ & Differential vertical deflection & $\begin{array}{c}\text { Absolute lateral } \\
\text { defection }\end{array}$ & $\begin{array}{c}\text { Absolute vertical } \\
\text { deflection }\end{array}$ \\
\hline SCI limits [7] & $\leq \mathrm{b} / 200$ & $\leq \mathrm{b} / 100$ and $\leq\left(\mathrm{b}^{2}+\mathrm{s}^{2}\right)^{0.5} / 125$ & $\leq \mathrm{h} / 100$ & - \\
\hline Industrial limits [8] & $\leq \mathrm{h} / 150$ & $\leq \mathrm{L} / 200$ & $\leq \mathrm{h} / 100$ & - \\
\hline
\end{tabular}

Notes:

b Frame spacing

h Column height

s Rafter length (column top to apex)

$\mathrm{L} \quad$ Span, between column bases 
Table 7 Parameters considered for frame geometry and actions

\begin{tabular}{|l|l|}
\hline Parameters & Values considered \\
\hline Span $(\mathrm{m})$ & $20,27.5,35,42.5,50$ \\
\hline Column height $(\mathrm{m})$ & $4,6,8,10$ \\
\hline Apex ratio & $0.5,0.6,0.7,0.8$ \\
\hline Snow load $\left(\mathrm{N} / \mathrm{m}^{2}\right)$ & $-200,-400,-600,-800$ \\
\hline Wind load scalar & $0.5,0.75,1,1.25,1.5$ \\
\hline PV loading $\left(\mathrm{N} / \mathrm{m}^{2}\right)$ & $-200,-400,-600,-800$ \\
\hline Permanent loading $\left(\mathrm{N} / \mathrm{m}^{2}\right)$ & $-200,-400,-600,-800$ \\
\hline Variable loading $\left(\mathrm{N} / \mathrm{m}^{2}\right)$ & -600 \\
\hline
\end{tabular}

*Varying the magnitude of the wind, using Belfast as a reference. 
Table 8 Percentage influence of ULS load combination (LCs) on different frame components

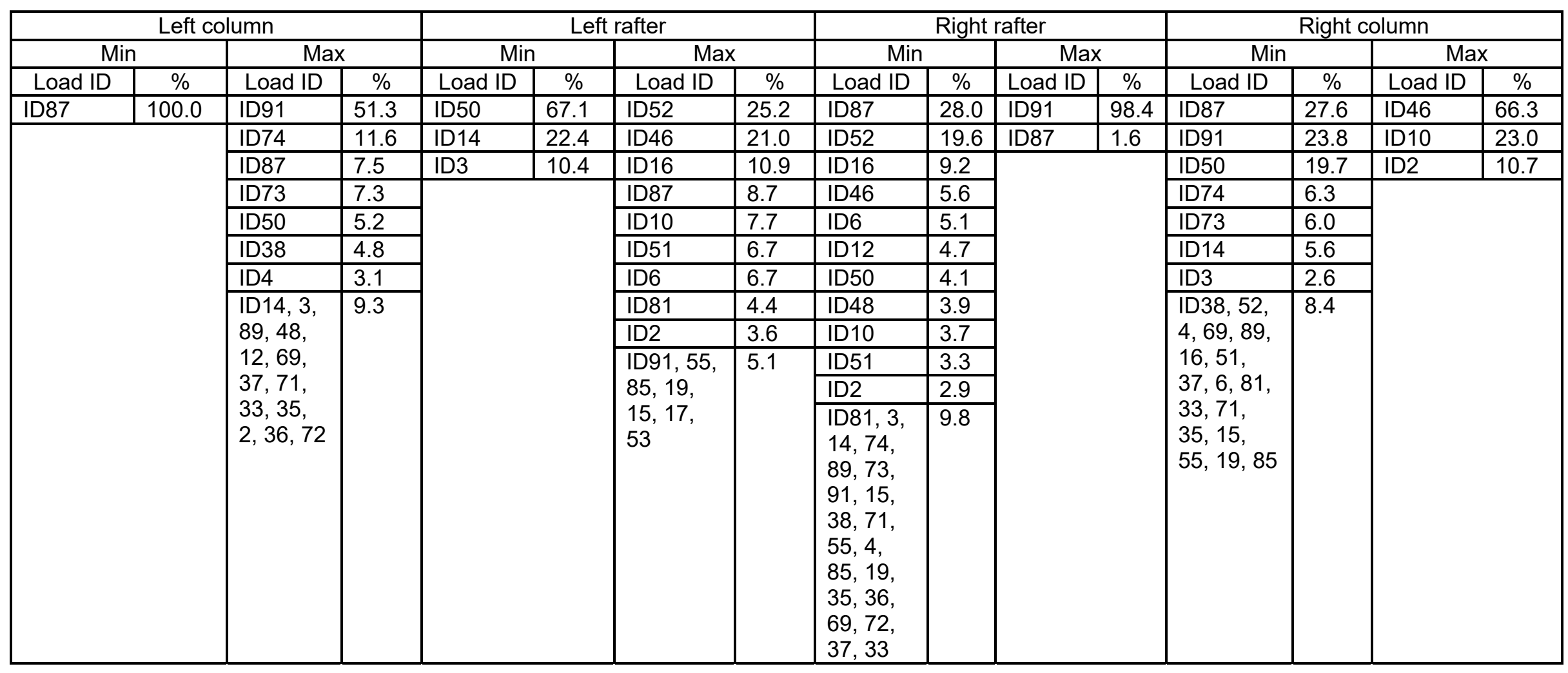


Table 9 Parameters of GA configuration

\begin{tabular}{|c|c|c|c|c|c|c|}
\hline \multirow[b]{2}{*}{ GA configuration } & \multirow[b]{2}{*}{ Number of design variables } & \multicolumn{2}{|c|}{ Population size } & \multirow[b]{2}{*}{ Elite count } & \multicolumn{2}{|c|}{ Termination criteria } \\
\hline & & Initial & Normal & & Maximum number of genrations & Stall generations limit ${ }^{*}$ \\
\hline C1 Rolled Frame & 6 & 288 & 36 & 4 & 100 & 20 \\
\hline C2 Fabricated Frame & 12 & 960 & 120 & 4 & 150 & 20 \\
\hline C3 Tapered Frame & 15 & 1440 & 180 & 6 & 150 & 20 \\
\hline
\end{tabular}

*The number of generation with no improvement before stopping the optimisation.

Table 10 Reliability of genetic algorithm for given population multiplier

\begin{tabular}{|c|c|c|c|c|c|}
\cline { 2 - 6 } \multicolumn{1}{c|}{} & \multicolumn{5}{c|}{ Population multiplier } \\
\cline { 2 - 7 } \multicolumn{1}{c|}{} & \multicolumn{5}{c|}{ Mean weight (kg per $\left.\mathrm{m}^{2}\right)$} \\
\hline \multirow{2}{*}{ GA } & \multicolumn{5}{c|}{ (Standard deviation) } \\
\hline \multirow{2}{*}{ C1 Rolled } & 216.72 & 18.58 & 16.82 & 16.51 & 16.64 \\
& $(240.94)$ & $(1.73)$ & $(0.40)$ & $(0.17)$ & $(0.19)$ \\
\hline \multirow{2}{*}{ C2 Fabricated } & 19.88 & 17.82 & 16.32 & 16.35 & 16.34 \\
& $(2.42)$ & $(1.53)$ & $(0.62)$ & $(0.59)$ & $(0.63)$ \\
\hline \multirow{2}{*}{ C3 Tapered } & 16.61 & 15.01 & 14.59 & 14.44 & 14.25 \\
& $(1.21)$ & $(0.70)$ & $(0.77)$ & $(0.72)$ & $(0.47)$ \\
\hline
\end{tabular}


Table 11 Reference frame optimum results

\begin{tabular}{|c|c|c|c|c|c|c|c|c|c|c|c|c|c|c|}
\hline \multirow[b]{4}{*}{$\begin{array}{l}\text { Apex } \\
\text { ratio }\end{array}$} & \multirow[b]{4}{*}{$\begin{array}{l}\text { Column } \\
\text { height }\end{array}$} & \multirow[b]{4}{*}{$\begin{array}{l}\text { Deflection } \\
\text { limits }\end{array}$} & \multicolumn{12}{|c|}{ Mass $\mathrm{kg} / \mathrm{m}^{2}$ (Standard deviation based on 8 runs) } \\
\hline & & & \multicolumn{4}{|c|}{ Universal beams (C1) } & \multicolumn{4}{|c|}{ Fabricated beams (C2) } & \multicolumn{4}{|c|}{ Tapered beams (C3) } \\
\hline & & & \multicolumn{2}{|c|}{ All ULS LCs } & \multicolumn{2}{|c|}{ ULS LCs 1-8 } & \multicolumn{2}{|c|}{ All ULS LCs } & \multicolumn{2}{|c|}{ ULS LCs 1-8 } & \multicolumn{2}{|c|}{ All ULS LCs } & \multicolumn{2}{|c|}{ ULS LCs $1-8$} \\
\hline & & & $\begin{array}{l}\text { PV - } \\
400\end{array}$ & $\begin{array}{l}\text { No } \\
\text { PV }\end{array}$ & $\begin{array}{l}\text { PV - } \\
400\end{array}$ & No PV & $\begin{array}{l}\text { PV - } \\
400\end{array}$ & $\begin{array}{l}\text { No } \\
\text { PV }\end{array}$ & $\begin{array}{l}\text { PV - } \\
400\end{array}$ & No PV & $\begin{array}{l}P V- \\
400\end{array}$ & $\begin{array}{l}\text { No } \\
\text { PV }\end{array}$ & $\begin{array}{l}P V- \\
400\end{array}$ & No PV \\
\hline 0.5 & 6 & None & $\begin{array}{l}14.47 \\
(0.56)\end{array}$ & $\begin{array}{l}13.3 \\
(0.33)\end{array}$ & $\begin{array}{l}13.21 \\
(0.16)\end{array}$ & $\begin{array}{l}12.12 \\
(0.35)\end{array}$ & $\begin{array}{l}13.84 \\
(0.5)\end{array}$ & $\begin{array}{l}13.07 \\
(0.51)\end{array}$ & $\begin{array}{l}12.77 \\
(0.55)\end{array}$ & \begin{tabular}{|l|}
11.49 \\
$(1.06)$
\end{tabular} & $\begin{array}{l}12.58 \\
(0.5)\end{array}$ & $\begin{array}{l}11.18 \\
(0.51)\end{array}$ & $\begin{array}{l}11.16 \\
(0.55)\end{array}$ & $\begin{array}{l}10.06 \\
(1.06)\end{array}$ \\
\hline 0.5 & 6 & IND & $\begin{array}{l}14.85 \\
(0.37)\end{array}$ & $\begin{array}{l}14.26 \\
(0.27)\end{array}$ & $\begin{array}{l}14.66 \\
(0.11)\end{array}$ & $\begin{array}{l}14.22 \\
(0.35)\end{array}$ & $\begin{array}{l}14.3 \\
(0.4)\end{array}$ & $\begin{array}{l}13.81 \\
(0.58)\end{array}$ & $\begin{array}{l}14.02 \\
(0.36)\end{array}$ & \begin{tabular}{|l|}
13.72 \\
$(0.81)$
\end{tabular} & $\begin{array}{l}13.66 \\
(0.4)\end{array}$ & \begin{tabular}{|l|}
13.49 \\
$(0.58)$
\end{tabular} & $\begin{array}{l}13.49 \\
(0.36)\end{array}$ & $\begin{array}{l}13.12 \\
(0.81)\end{array}$ \\
\hline 0.5 & 6 & $\mathrm{SCl}$ & $\begin{array}{l}18.69 \\
(0.3)\end{array}$ & $\begin{array}{l}18.74 \\
(0.29)\end{array}$ & $\begin{array}{l}18.71 \\
(0.42)\end{array}$ & $\begin{array}{l}18.95 \\
(0.24)\end{array}$ & $\begin{array}{l}17.39 \\
(0.15)\end{array}$ & $\begin{array}{l}17.65 \\
(0.22)\end{array}$ & \begin{tabular}{|l|}
17.51 \\
$(0.81)$
\end{tabular} & $\begin{array}{l}17.27 \\
(0.68)\end{array}$ & $\begin{array}{l}15.75 \\
(0.15)\end{array}$ & $\begin{array}{l}16.3 \\
(0.22)\end{array}$ & $\begin{array}{l}15.75 \\
(0.81)\end{array}$ & $\begin{array}{l}16.3 \\
(0.68)\end{array}$ \\
\hline 0.8 & 6 & None & $\begin{array}{l}15.15 \\
(1)\end{array}$ & $\begin{array}{l}13 . \overline{4} 5 \\
(0.46)\end{array}$ & $\begin{array}{l}14.75 \\
(0.18)\end{array}$ & $\begin{array}{l}12.25 \\
(0.18)\end{array}$ & $\begin{array}{l}15.32 \\
(0.65)\end{array}$ & $\begin{array}{l}13.79 \\
(0.67)\end{array}$ & $\begin{array}{l}14.22 \\
(0.81)\end{array}$ & $\begin{array}{l}12 . \overline{62} \\
(0.44)\end{array}$ & $\begin{array}{l}13.42 \\
(0.65)\end{array}$ & $\begin{array}{l}11.71 \\
(0.67)\end{array}$ & $\begin{array}{l}12.75 \\
(0.81)\end{array}$ & $\begin{array}{l}10.61 \\
(0.44)\end{array}$ \\
\hline 0.8 & 6 & IND & $\begin{array}{l}16.5 \\
(0.27)\end{array}$ & $\begin{array}{l}15.14 \\
(0.53)\end{array}$ & $\begin{array}{l}15.68 \\
(0.3)\end{array}$ & $\begin{array}{l}15.37 \\
(0.57)\end{array}$ & \begin{tabular}{|l|}
16.77 \\
$(0.44)$
\end{tabular} & $\begin{array}{l}16.22 \\
(0.37)\end{array}$ & \begin{tabular}{|l|}
15.78 \\
$(0.11)$
\end{tabular} & $\begin{array}{l}15.99 \\
(0.2)\end{array}$ & $\begin{array}{l}15.17 \\
(0.44)\end{array}$ & $\begin{array}{l}14.21 \\
(0.37)\end{array}$ & $\begin{array}{l}14.11 \\
(0.11)\end{array}$ & $\begin{array}{l}13.97 \\
(0.2)\end{array}$ \\
\hline 0.8 & 6 & $\mathrm{SCl}$ & $\begin{array}{l}20.46 \\
(0.28)\end{array}$ & $\begin{array}{l}20.37 \\
(0.8)\end{array}$ & $\begin{array}{l}20.35 \\
(0.84)\end{array}$ & $\begin{array}{l}20.16 \\
(0.93)\end{array}$ & \begin{tabular}{|l|}
19.96 \\
$(0.19)$
\end{tabular} & $\begin{array}{l}19.81 \\
(0.34)\end{array}$ & \begin{tabular}{|l|}
19.54 \\
$(0.44)$
\end{tabular} & $\begin{array}{l}19.96 \\
(0.66)\end{array}$ & \begin{tabular}{|l|}
17.54 \\
$(0.19)$
\end{tabular} & $\begin{array}{l}17.21 \\
(0.34)\end{array}$ & $\begin{array}{l}17.2 \\
(0.44)\end{array}$ & $\begin{array}{l}16.86 \\
(0.66)\end{array}$ \\
\hline 0.5 & 12 & None & $\begin{array}{l}27.28 \\
(1)\end{array}$ & $\begin{array}{l}25.98 \\
(0.45)\end{array}$ & $\begin{array}{l}17 . \overline{9} \\
(0.28)\end{array}$ & $\begin{array}{l}16.78 \\
(0.16)\end{array}$ & $\begin{array}{l}26.29 \\
(0.81)\end{array}$ & $\begin{array}{l}25.09 \\
(1.95)\end{array}$ & $\begin{array}{l}17.67 \\
(0.76)\end{array}$ & $\begin{array}{l}15.89 \\
(0.55)\end{array}$ & $\begin{array}{l}23.37 \\
(0.81)\end{array}$ & $\begin{array}{l}22.4 \\
(1.95)\end{array}$ & $\begin{array}{l}14.06 \\
(0.76)\end{array}$ & $\begin{array}{l}13.02 \\
(0.55)\end{array}$ \\
\hline 0.5 & 12 & IND & $\begin{array}{l}42.17 \\
(1.37)\end{array}$ & $\begin{array}{l}42.23 \\
(0.49)\end{array}$ & $\begin{array}{l}42.25 \\
(0.91)\end{array}$ & $\begin{array}{l}43.09 \\
(0.94)\end{array}$ & $\begin{array}{l}38.46 \\
(2.03)\end{array}$ & $\begin{array}{l}38.21 \\
(1.82)\end{array}$ & $\begin{array}{l}38.96 \\
(5.46)\end{array}$ & \begin{tabular}{|l|}
38.94 \\
$(5.39)$
\end{tabular} & \begin{tabular}{|l|}
36.75 \\
$(2.03)$
\end{tabular} & $\begin{array}{l}36.84 \\
(1.82)\end{array}$ & $\begin{array}{l}36.75 \\
(5.46)\end{array}$ & $\begin{array}{l}36.81 \\
(5.39)\end{array}$ \\
\hline 0.5 & 12 & $\mathrm{SCl}$ & \begin{tabular}{|l|}
75.85 \\
$(1.12)$
\end{tabular} & $\begin{array}{l}75.83 \\
(0.8)\end{array}$ & $\begin{array}{l}75.85 \\
(1.17)\end{array}$ & $\begin{array}{l}75.76 \\
(2.29)\end{array}$ & $\begin{array}{l}61.1 \\
(1.65)\end{array}$ & $\begin{array}{l}61.5 \\
(2.97)\end{array}$ & \begin{tabular}{|l|}
62 \\
$(2,14)$
\end{tabular} & $\begin{array}{l}62 \\
(17.37)\end{array}$ & $\begin{array}{l}60.74 \\
(1.65)\end{array}$ & \begin{tabular}{|l|}
59.78 \\
$(2.97)$
\end{tabular} & $\begin{array}{l}58.14 \\
(0.14)\end{array}$ & $\begin{array}{l}57.8 \\
(17.37)\end{array}$ \\
\hline 0.8 & 12 & None & $\begin{array}{l}28.18 \\
(1.02)\end{array}$ & $\begin{array}{l}25.84 \\
(0.27)\end{array}$ & $\begin{array}{l}19.01 \\
(0.2)\end{array}$ & $\begin{array}{l}16.5 \\
(0.92)\end{array}$ & $\begin{array}{l}27.47 \\
(1.19)\end{array}$ & $\begin{array}{l}25.88 \\
(0.89)\end{array}$ & $\begin{array}{l}19.18 \\
(0.95)\end{array}$ & $\begin{array}{l}16 . \overline{38} \\
(0.65)\end{array}$ & $\begin{array}{l}24.2 \\
(1.19)\end{array}$ & $\begin{array}{l}23.4 \overline{5} \\
(0.89)\end{array}$ & $\begin{array}{l}16.95 \\
(0.95)\end{array}$ & $\begin{array}{l}13.85 \\
(0.65)\end{array}$ \\
\hline 0.8 & 12 & IND & \begin{tabular}{|l}
44.7 \\
$(0.85)$
\end{tabular} & $\begin{array}{l}44.8 \\
(0.72) \\
\end{array}$ & $\begin{array}{l}44.35 \\
(0.86)\end{array}$ & $\begin{array}{l}44.27 \\
(0.94)\end{array}$ & $\begin{array}{l}41.94 \\
(1.16)\end{array}$ & $\begin{array}{l}40.65 \\
(5.26)\end{array}$ & \begin{tabular}{|l|}
40.37 \\
$(4.45)$
\end{tabular} & \begin{tabular}{|l|}
41.26 \\
$(2.6)$
\end{tabular} & $\begin{array}{l}38.3 \\
(1.16)\end{array}$ & $\begin{array}{l}38.05 \\
(5.26)\end{array}$ & $\begin{array}{l}38.3 \\
(4.45)\end{array}$ & $\begin{array}{l}39.07 \\
(2.6)\end{array}$ \\
\hline 0.8 & 12 & $\mathrm{SCl}$ & $\begin{array}{l}79.51 \\
(1.06)\end{array}$ & $\begin{array}{l}79.37 \\
(1.45) \\
\end{array}$ & $\begin{array}{l}79.42 \\
(2.04)\end{array}$ & $\begin{array}{l}79.46 \\
(1.28)\end{array}$ & \begin{tabular}{|l|}
66.7 \\
$(1.65)$
\end{tabular} & $\begin{array}{l}64.86 \\
(1.83)\end{array}$ & \begin{tabular}{|l|}
67 \\
$(4.17)$
\end{tabular} & $\begin{array}{l}67 \\
(10.05)\end{array}$ & $\begin{array}{l}62.07 \\
(1.65)\end{array}$ & $\begin{array}{l}63.71 \\
(1.83)\end{array}$ & $\begin{array}{l}62.45 \\
(4.17)\end{array}$ & $\begin{array}{l}60.72 \\
(7.05)\end{array}$ \\
\hline
\end{tabular}


Table 12 Percentage increase going from symmetric to asymmetric topography

\begin{tabular}{|c|c|c|c|c|c|c|c|c|c|c|c|c|c|}
\hline \multirow[b]{3}{*}{$\begin{array}{l}\text { Column } \\
\text { height } \\
(\mathrm{m})\end{array}$} & \multirow[b]{3}{*}{$\begin{array}{l}\text { Deflection } \\
\text { limits }\end{array}$} & \multicolumn{4}{|c|}{ Universal beams ( $\mathrm{C} 1)$} & \multicolumn{4}{|c|}{ Fabricated beams (C2) } & \multicolumn{4}{|c|}{ Tapered beams (C3) } \\
\hline & & \multicolumn{2}{|c|}{ All ULS LCs } & \multicolumn{2}{|c|}{ ULS LCs 1-8 } & \multicolumn{2}{|c|}{ All ULS LCs } & \multicolumn{2}{|c|}{ ULS LCs $1-8$} & \multicolumn{2}{|c|}{ All ULS LCs } & \multicolumn{2}{|c|}{ ULS LCs 1-8 } \\
\hline & & PV-400 & No PV & $P V-400$ & No PV & PV-400 & No PV & $P V-400$ & No PV & PV-400 & No PV & PV -400 & $\begin{array}{l}\text { No } \\
\text { PV }\end{array}$ \\
\hline 6 & None & $4.7 \%$ & $1.1 \%$ & $11.7 \%$ & $1.1 \%$ & $10.7 \%$ & $5.5 \%$ & $11.4 \%$ & $9.8 \%$ & $6.7 \%$ & $4.7 \%$ & $14.2 \%$ & $5.5 \%$ \\
\hline 6 & IND & $11.1 \%$ & $6.2 \%$ & $7.0 \%$ & $8.1 \%$ & $17.3 \%$ & $17.5 \%$ & $12.6 \%$ & $16.5 \%$ & $11.1 \%$ & $5.3 \%$ & $4.6 \%$ & $6.5 \%$ \\
\hline 6 & $\mathrm{SCl}$ & $9.5 \%$ & $8.7 \%$ & $8.8 \%$ & $6.4 \%$ & $14.8 \%$ & $12.2 \%$ & $11.6 \%$ & $15.6 \%$ & $11.4 \%$ & $5.6 \%$ & $9.2 \%$ & $3.4 \%$ \\
\hline 12 & $\mathrm{SCl}$ & $4.8 \%$ & $4.7 \%$ & $4.7 \%$ & $4.9 \%$ & $9.2 \%$ & $-5.2 \%$ & $8.1 \%$ & $8.1 \%$ & $2.2 \%$ & $6.6 \%$ & $7.4 \%$ & $5.1 \%$ \\
\hline
\end{tabular}


Table 13 Percentage weight increase due to PV loading

\begin{tabular}{|c|c|c|c|c|c|c|c|c|}
\hline \multirow[b]{2}{*}{$\begin{array}{l}\text { Apex } \\
\text { ratio }\end{array}$} & \multirow[b]{2}{*}{$\begin{array}{l}\text { Column } \\
\text { height } \\
(\mathrm{m})\end{array}$} & \multirow[b]{2}{*}{$\begin{array}{l}\text { Deflection } \\
\text { limits }\end{array}$} & \multicolumn{2}{|c|}{$\begin{array}{l}\text { Universal beams } \\
\text { (C1) }\end{array}$} & \multicolumn{2}{|c|}{$\begin{array}{l}\text { Fabricated } \\
\text { beams (C2) }\end{array}$} & \multicolumn{2}{|c|}{$\begin{array}{l}\text { Tapered beams } \\
\text { (C3) }\end{array}$} \\
\hline & & & $\begin{array}{l}\text { All } \\
\text { ULS } \\
\text { LCs } \\
\end{array}$ & $\begin{array}{l}\text { ULS } \\
\text { LCs 1- } \\
8\end{array}$ & $\begin{array}{l}\text { All } \\
\text { ULS } \\
\text { LCs }\end{array}$ & $\begin{array}{l}\text { ULS } \\
\text { LCs 1- } \\
8\end{array}$ & $\begin{array}{l}\text { All ULS } \\
\text { LCs }\end{array}$ & $\begin{array}{l}\text { ULS } \\
\text { LCs } \\
1-8 \\
\end{array}$ \\
\hline 0.5 & 6 & None & $8.8 \%$ & $9.0 \%$ & $5.9 \%$ & $11.1 \%$ & $12.5 \%$ & $10.9 \%$ \\
\hline 0.5 & 6 & IND & $4.1 \%$ & $3.1 \%$ & $3.5 \%$ & $2.2 \%$ & $1.3 \%$ & $2.8 \%$ \\
\hline 0.5 & 6 & $\mathrm{SCl}$ & $-0.3 \%$ & $-1.3 \%$ & $-1.5 \%$ & $1.4 \%$ & $-3.4 \%$ & $-3.4 \%$ \\
\hline 0.8 & 6 & None & $12.6 \%$ & $20.4 \%$ & $11.1 \%$ & $12.7 \%$ & $14.6 \%$ & $20.2 \%$ \\
\hline 0.8 & 6 & IND & $9.0 \%$ & $2.0 \%$ & $3.4 \%$ & $-1.3 \%$ & $6.8 \%$ & $1.0 \%$ \\
\hline 0.8 & 6 & $\mathrm{SCl}$ & $0.4 \%$ & $0.9 \%$ & $0.8 \%$ & $-2.1 \%$ & $1.9 \%$ & $2.0 \%$ \\
\hline 0.5 & 12 & None & $5.0 \%$ & $7.1 \%$ & $4.8 \%$ & $11.2 \%$ & $4.3 \%$ & $8.0 \%$ \\
\hline 0.5 & 12 & IND & $-0.1 \%$ & $-1.9 \%$ & $0.7 \%$ & $0.1 \%$ & $-0.2 \%$ & $-0.2 \%$ \\
\hline 0.5 & 12 & $\mathrm{SCl}$ & $0.0 \%$ & $0.1 \%$ & $-0.7 \%$ & $0.0 \%$ & $1.6 \%$ & $0.6 \%$ \\
\hline 0.8 & 12 & None & $9.1 \%$ & $15.2 \%$ & $6.1 \%$ & $17.1 \%$ & $3.2 \%$ & $22.4 \%$ \\
\hline 0.8 & 12 & IND & $-0.2 \%$ & $0.2 \%$ & $3.2 \%$ & $-2.2 \%$ & $0.7 \%$ & $-2.0 \%$ \\
\hline 0.8 & 12 & $\mathrm{SCl}$ & $0.2 \%$ & $-0.1 \%$ & $2.8 \%$ & $0.0 \%$ & $-2.6 \%$ & $2.8 \%$ \\
\hline
\end{tabular}


Table 14 Weight increase going from ULS load combination 1-8 to all ULS load combination

\begin{tabular}{|c|c|c|c|c|c|c|c|c|}
\hline \multirow[b]{2}{*}{$\begin{array}{l}\text { Apex } \\
\text { ratio }\end{array}$} & \multirow[b]{2}{*}{$\begin{array}{l}\text { Column } \\
\text { height } \\
(\mathrm{m})\end{array}$} & \multirow[b]{2}{*}{$\begin{array}{l}\text { Deflection } \\
\text { limits }\end{array}$} & \multicolumn{2}{|c|}{$\begin{array}{l}\text { Universal beams } \\
\text { (C1) }\end{array}$} & \multicolumn{2}{|c|}{$\begin{array}{l}\text { Fabricated beams } \\
\text { (C2) }\end{array}$} & \multicolumn{2}{|c|}{$\begin{array}{l}\text { Tapered beams } \\
\text { (C3) }\end{array}$} \\
\hline & & & PV-400 & No PV & PV-400 & No PV & PV-400 & No PV \\
\hline 0.5 & 6 & None & $9.5 \%$ & $9.74 \%$ & $8.38 \%$ & $13.7 \%$ & $12.7 \%$ & $11.1 \%$ \\
\hline 0.5 & 6 & IND & $1.30 \%$ & $0.28 \%$ & $2.00 \%$ & $0.66 \%$ & $1.26 \%$ & $2.82 \%$ \\
\hline$\frac{0.5}{0.8}$ & $\frac{6}{6}$ & $\frac{\mathrm{SCl}}{\text { None }}$ & $\begin{array}{l}-0.11 \% \\
2.71 \% \\
\end{array}$ & $\frac{-1.11 \%}{9.80 \%}$ & $\frac{-0.69 \%}{7.74 \%}-$ & $\frac{2.20 \%}{9.27 \%}$ & $\frac{0.00 \%}{5.25 \%}$ & $\frac{0.00 \%}{10.3 \%}=$ \\
\hline 0.8 & 6 & IND & $5.23 \%$ & $-1.50 \%$ & $6.27 \%$ & $1.44 \%$ & $7.51 \%$ & $1.72 \%$ \\
\hline$\frac{0.8}{0.5}-$ & $\frac{6}{12}$ & $\frac{\mathrm{SCl}}{\text { None }}$ & $\frac{0.54 \%}{51.8 \%}$ & $\frac{1.04 \%}{54.8 \%}$ & $\frac{2.15 \%}{48.7 \%}=$ & $\begin{array}{l}-0.75 \% \\
57.9 \%\end{array}$ & $\frac{1.98 \%}{66.2 \%}$ & $\frac{2.08 \%}{72.0 \%}=$ \\
\hline 0.5 & 12 & IND & $-0.19 \%$ & $-2.00 \%$ & $-1.28 \%$ & $-1.87 \%$ & $0.00 \%$ & $0.08 \%$ \\
\hline$\frac{0.5}{0.8}$ & $\frac{12}{12}-$ & $\frac{\mathrm{SCl}}{\text { None }}$ & $\frac{0.00 \%}{48.2 \%}$ & $\frac{0.09 \%}{56.6 \%}$ & $\begin{array}{l}-1.45 \% \\
\mathbf{4 3 . 2} \%\end{array}$ & $\begin{array}{l}-0.81 \% \\
\mathbf{5 8 . 0} \%\end{array}$ & $\frac{4.47 \%}{42.8 \%}$ & $\frac{3.43 \%}{69.3 \%}$ \\
\hline 0.8 & 12 & IND & $0.79 \%$ & $1.20 \%$ & $3.89 \%$ & $-1.48 \%$ & $0.00 \%$ & $-2.61 \%$ \\
\hline 0.8 & 12 & $\mathrm{SCl}$ & $0.11 \%$ & $-0.11 \%$ & $-0.45 \%$ & $-3.19 \%$ & $-0.61 \%$ & $4.92 \%$ \\
\hline
\end{tabular}

